\title{
Auditory event-related potentials and associations with sensory patterns in children with autism spectrum disorder, developmental delay, and typical development
}

Citation for published version (APA):

Donkers, F. C. L., Carlson, M., Schipul, S. E., Belger, A., \& Baranek, G. T. (2020). Auditory event-related potentials and associations with sensory patterns in children with autism spectrum disorder, developmental delay, and typical development. Autism, 24(5), 1093-1110. https://doi.org/10.1177/1362361319893196

Document status and date:

Published: 01/07/2020

DOI:

$10.1177 / 1362361319893196$

Document Version:

Publisher's PDF, also known as Version of record

Document license:

Taverne

Please check the document version of this publication:

- A submitted manuscript is the version of the article upon submission and before peer-review. There can be important differences between the submitted version and the official published version of record. People interested in the research are advised to contact the author for the final version of the publication, or visit the DOI to the publisher's website.

- The final author version and the galley proof are versions of the publication after peer review.

- The final published version features the final layout of the paper including the volume, issue and page numbers.

Link to publication

\footnotetext{
General rights rights.

- You may freely distribute the URL identifying the publication in the public portal. please follow below link for the End User Agreement:

www.umlib.nl/taverne-license

Take down policy

If you believe that this document breaches copyright please contact us at:

repository@maastrichtuniversity.nl

providing details and we will investigate your claim.
}

Copyright and moral rights for the publications made accessible in the public portal are retained by the authors and/or other copyright owners and it is a condition of accessing publications that users recognise and abide by the legal requirements associated with these

- Users may download and print one copy of any publication from the public portal for the purpose of private study or research.

- You may not further distribute the material or use it for any profit-making activity or commercial gain

If the publication is distributed under the terms of Article 25fa of the Dutch Copyright Act, indicated by the "Taverne" license above, 


\title{
Auditory event-related potentials and associations with sensory patterns in children with autism spectrum disorder, developmental delay, and typical development
}

2020, Vol. 24(5) 1093-1II0

(C) The Author(s) 2019

Article reuse guidelines:

sagepub.com/journals-permissions DOI: $10.1177 / 1362361319893196$ journals.sagepub.com/home/aut

(\$)SAGE

\author{
Franc CL Donkers',2 (D) Mike Carlson³, Sarah E Schipul', Aysenil \\ Belger $^{1,4}$, and Grace T Baranek',3 iD
}

\begin{abstract}
Atypical sensory response patterns are common in children with autism and developmental delay. Expanding on previous work, this observational electroencephalogram study assessed auditory event-related potentials and their associations with clinically evaluated sensory response patterns in children with autism spectrum disorder $(n=28)$, developmental delay $(n=17)$, and typical development $(n=39)$. Attention-orienting P3a responses were attenuated in autism spectrum disorder relative to both developmental delay and typical development, but early sensory $\mathrm{N} 2$ responses were attenuated in both autism spectrum disorder and developmental delay relative to typical development. Attenuated event-related potentials involving N2 or $\mathrm{P} 3$ a components, or a $\mathrm{PI} \times \mathrm{N} 2$ interaction, were related to more severe hyporesponsive or sensory-seeking response patterns across children with autism spectrum disorder and developmental delay. Thus, although attentional disruptions may be unique to autism spectrum disorder, sensory disruptions appear across developmental delay and are associated with atypical sensory behaviors.
\end{abstract}

\section{Lay abstract}

Atypical sensory behaviors are common in autism spectrum disorder and developmental delay. To date, it remains unclear whether sensory abnormalities are specific to autism spectrum disorder or reflect a broader pattern related to developmental disability in general. In this study, brain electrical responses to rarely occurring (novel) sounds and clinically evaluated sensory response patterns were investigated in 28 children with autism spectrum disorder, 17 children with developmental delay, and 39 typically developing children (typical development). Results showed that brain responses related to attention orienting were smaller in autism spectrum disorder relative to both developmental delay and typical development, but brain responses related to sensory processing were smaller in both autism spectrum disorder and developmental delay relative to typical development. The smaller brain responses were related to more severe sensory abnormalities across children with autism spectrum disorder and developmental delay. Thus, although brain attentional abnormalities may be unique to autism spectrum disorder, brain sensory abnormalities appear across developmental delay and are associated with atypical sensory behaviors.

\section{Keywords}

autism spectrum disorders, development, sensory impairments

'The University of North Carolina at Chapel Hill, USA

2Maastricht University, The Netherlands

${ }^{3}$ University of Southern California, USA

${ }^{4}$ Duke University, USA
Corresponding author:

Grace T Baranek, USC Mrs. T.H. Chan Division of Occupational Science and Occupational Therapy, University of Southern California, 1540 Alcazar Street, CHP-133, Los Angeles, CA 90089, USA.

Email: chair@chan.usc.edu 
Autism spectrum disorder (ASD) is characterized by core deficits in social communication and interaction and restricted, repetitive patterns of behavior, which include atypical sensory features (Diagnostic and Statistical Manual of Mental Disorders (5th ed.; DSM-5); American Psychiatric Association, 2013). The neural correlates underlying atypical sensory responses in ASD are currently being explored. Previous investigations have identified attenuated auditory event-related potentials (ERPs) in children with ASD compared to typically developing children and related these to sensory patterns (Donkers et al., 2015). However, it remains unclear how the neural correlates of sensory processing differ between children with ASD and children with more general developmental delay (DD). In this update to our previous work, we report auditory ERPs and their relation to sensory response patterns in children with autism and children with DD.

Compromised early auditory experience is a key concern in ASD because it is a likely precursor to impaired speech and language and may contribute to cascading neurophysiological changes associated with further abnormalities such as impaired social engagements (Jeste \& Nelson, 2009; Marco et al., 2011). Several reviews of auditory deficits in children with ASD have reported mixed findings, which may potentially stem from between-study differences in experimental procedures or participant characteristics such as age, autism severity, or language level (Bomba \& Pang, 2004; Jeste \& Nelson, 2009; Marco et al., 2011). However, the bulk of evidence suggests that neural processes involved in auditory processing are atypical in ASD (O'Connor, 2012).

Aberrant cortical information processing in ASD can be indexed at early sensory levels as well as higher-order frontal and association cortical levels, potentially mapping onto difficulties in both sensory and attentional filtering processes (Bruneau et al., 1999; Donkers et al., 2015; Kemner et al., 1995; Russo et al., 2010, 2012). Electroencephalogram (EEG) studies using the oddball paradigm, which consists of embedding infrequent stimuli within the presentation of more frequent (typically $80 \%$ or more) standard stimuli, provide evidence of deficient early auditory processing in children with ASD. These deficiencies include aberrant neural oscillatory-evoked activity and inter-trial coherence across multiple frequencies (Duffy \& Als, 2012), as well as decreased amplitude of $\mathrm{P} 1$ and $\mathrm{N} 2$ peak responses, ${ }^{1}$ which reflect pre-attentive sound detection occurring between approximately 50 and $250 \mathrm{~ms}$ following stimulus presentation (Bruneau et al., 1999; Donkers et al., 2015). An additional finding is the blunting of the P3a response, an ERP component which occurs after the P1-N2 cycle and reflects higher-order attentional processing (O'Connor, 2012). In contrast to these commonly observed deficits, evidence for differences in the latency of early responding to auditory signals has been inconsistent, with multiple studies showing opposite directions of effect in comparing children with ASD to TD controls (Marco et al., 2011).

Despite the presence of significant cognitive and intellectual impairments in many ASD children, auditory ERP studies have typically not included a DD control group. Therefore, it remains unclear which reported neural or sensory abnormalities are specific to ASD, as opposed to reflecting a broader pattern related to developmental disability in general. Knowledge of outcomes that are specific to ASD can inform theory regarding etiology and pathogenesis, increase diagnostic precision, and stimulate improved treatment in areas such as sensory integration, language, and communication. The inclusion of a DD control group is particularly valuable in that members of this population tend to have more restricted intellectual and adaptive development than children with ASD. Given this direction of effect, any observation of greater EEG abnormalities in the ASD group is especially indicative of differences uniquely associated with ASD, as such a result could not be attributed to general developmental disadvantage.

Few studies have investigated the association between clinically defined sensory features and specific neurophysiological markers in children with ASD or DD. Varied sensory features are reported across modalities in children with ASD (Ausderau et al., 2014; Baranek et al., 2006; Ben-Sasson et al., 2009; O'Donnell et al., 2012; Schoen \& Miller, 2009) and are commonly categorized into observable sensory response patterns such as under-reactivity (hyporesponsiveness); over-reactivity (hyperresponsiveness); and sensory interests, repetitions, and seeking behaviors (Ausderau et al., 2014; Lane et al., 2011; Liss et al., 2006). Underscoring the potential connection between auditory abnormalities and sensory features, the results of a recent study indicated that attenuated N2 and $\mathrm{P} 3 \mathrm{a}$ amplitudes in the context of specific ranges of P1 predicted greater sensory seeking behaviors for children with ASD (Donkers et al., 2015). The current research was in part designed to examine how auditory dysfunction is related to downstream behavioral abnormalities in ASD, thereby addressing a previously identified knowledge gap (Jeste \& Nelson, 2009; O'Connor, 2012).

In this study, children with ASD, DD, or typical development (TD) participated in a passive auditory oddball paradigm involving standard, pitch-deviant, durationdeviant, and novel tones. ERPs were calculated for early sensory P1 and N2 responses to standard and deviant tones, as well as for attention-orienting $\mathrm{P} 3 \mathrm{a}$ responses to novel sounds ( $\mathrm{N} 1$ and $\mathrm{P} 2$ responses were not included due to their common absence in children below 9 years of age). In addition, observational measures of sensory response patterns were collected. We examined differences in mean ERP amplitude between groups, as well as their association with sensory response patterns in children with ASD or DD. 
Table I. Background characteristics by group.

\begin{tabular}{lcccc}
\hline & ASD $(n=28)$ & DD $(n=17)$ & TD $(n=39)$ & Group effect \\
\hline CA (SD) & $7.6 \pm 2.2$ & $7.7 \pm 2.7$ & $7.0 \pm 2.0$ & $F(2,81)=0.74, p=0.48$ \\
MA (SD) & $6.1 \pm 3.5$ & $3.9 \pm 1.5$ & $8.2 \pm 3.8$ & $F(2,80)=10.02, p<0.001$ \\
NVIQ $(S D)^{\mathrm{a}}$ & $81.3 \pm 24.2$ & $61.7 \pm 15.0$ & $108.9 \pm 12.9$ & $F(2,75)=38.51, p<0.001$ \\
M:F & $22: 6$ & $9: 8$ & $30: 9$ & FEP test, $p=0.15$ \\
ADOS severity (SD) & $8.1 \pm 1.8$ & $1.5 \pm 0.6$ & - & $t(43)=17.59, p<0.001$ \\
\hline
\end{tabular}

ASD: autism spectrum disorder; DD: developmental delay; TD: typical development; CA: chronological age; MA: mental age; M:F: male-tofemale ratio; NVIQ: non-verbal IQ; FEP: Freeman-Halton extension of Fisher's exact probability test for $2 \times 3$ tables; ADOS: Autism Diagnostic Observation Schedules.

${ }^{a}$ All pairs of group means differ from each other beyond the 0.05 significance level.

We hypothesized that amplitudes are attenuated for: (a) early sensory EEG-based responses (P1 and N2) to standard, pitch-deviant, and duration-deviant sounds in children with either ASD or DD relative to those with TD; and (b) higher-order attentional EEG-based responses (P3a) to novel sounds in children with ASD in comparison to both DD and TD populations. These hypotheses reflect prior research outcomes indicating dampened auditory ERPs in children with ASD relative to TD children, the observation of generalized elevated hyporesponsiveness in children with ASD relative to those with DD, and the compromised neurophysiology underlying higher-order information processing in ASD. We further hypothesized that the degree of response attenuation in $\mathrm{P} 1, \mathrm{~N} 2$, and/or $\mathrm{P} 3$ is positively associated with the extent of overt sensory symptomatology in children with ASD or DD. However, due to inconsistencies in the existing literature, we did not formulate hypotheses pertaining to ERP latencies.

\section{Methods}

This cross-sectional study tested group differences in ERP responses using an experimental lab paradigm and utilized correlational analyses with observational measures.

\section{Participants}

Eighty-four children aged 4-12 years participated in this study, including 28 with ASD, 17 with DD, and 39 TD. Children were recruited via a university research registry as well as through flyers posted with local advocacy groups, clinics, and listservs. Results comparing the ASD and TD groups have been published previously (Donkers et al., 2015); the DD group was newly added for the current analysis. An additional 28 children (17 ASD, 4 DD, and 7 TD) participated, but were excluded due to the inability to tolerate electrodes for eye movement data, excessive participant motion, lack of tolerance for the electrode cap, error in testing equipment, discomfort with performing the task, or presence of a prior hearing problem. Sample size was based on power analyses as well as feasibility/expense of recruiting specific comparison groups during the timeline of the grant-funded project (2008-2014). All participants in the ASD group were diagnosed by a licensed psychologist or physician and met algorithm cutoffs for "autism" on both the Autism Diagnostic Interview-Revised (ADI-R; Lord et al., 1994) and the Autism Diagnostic Observation Schedules-2 (ADOS-2; Gotham et al., 2009; Lord et al., 2006, 2012). The ADI-R and ADOS-2 were administered by research reliable testers who were trained by a certified instructor. The DD group included 10 children with Down syndrome and 7 with other DD diagnoses. (Within the DD group, children with Down syndrome vs other DD did not differ in demographic/individual characteristics or ERP outcomes (all $p$-values $>0.60$ ).) Children in the TD group had no history of DDs and scored in the normal range on cognitive and adaptive measures. Participants in both the DD and TD groups had no significant symptoms of autism as confirmed by the Childhood Autism Rating Scale (CARS; Schopler et al., 1986), as well as the ADOS-2 for the DD group. Children were excluded from all three groups if they had seizure disorders, physical impairments, uncorrected vision or hearing impairments, psychotic disorders, fragile $\mathrm{X}$ syndrome, or were taking antipsychotic medications.

Background characteristics of the ASD, DD, and TD groups are reported in Table 1. The study controlled for bias with rigorous inclusion/exclusion criteria, age matching across groups, and statistical control for potential confounding variables. The three groups did not differ in chronological age $(p>0.40)$ or gender ratio (due to oversampling of males in the TD group to increase control; $p=0.15)$. The three groups differed in mental age (MA) with developmental levels highest for the TD group, followed by the ASD and DD groups ( $p<0.05$ for all pairwise comparisons). Calibrated ADOS severity scores (Gotham et al., 2009) were significantly higher for the ASD versus DD group $(p<0.001)$, as expected due to exclusion criterion for children in the DD group with clinically elevated levels of autism symptomatology.

The experimental protocol was approved by the institutional review boards of University of North Carolina, Chapel Hill and University of Southern California. All 
Table 2. Mean $\pm S D$ of sensory measures by group.

\begin{tabular}{|c|c|c|c|c|c|c|c|c|c|c|}
\hline & \multirow{2}{*}{$\begin{array}{l}\text { ASD } \\
(n=28) \\
M(S D)\end{array}$} & \multirow{2}{*}{$\begin{array}{l}\mathrm{DD} \\
(n=13)^{\mathrm{a}} \\
M(S D)\end{array}$} & \multirow{2}{*}{$\begin{array}{l}\text { TD }(n=39) \\
M(S D)\end{array}$} & \multirow{2}{*}{$\begin{array}{l}\text { One-way } \\
\text { ANOVA: } \\
F(2,77)\end{array}$} & \multicolumn{2}{|c|}{ ASD vs DD } & \multicolumn{2}{|c|}{ ASD vs TD } & \multicolumn{2}{|c|}{ DD vs TD } \\
\hline & & & & & $t(39)$ & $p$ & $t(65)$ & $p$ & $t(50)$ & $p$ \\
\hline Hyporesponsive & $2.1 \pm 0.7$ & $1.6 \pm 0.8$ & $1.7 \pm 0.6$ & $3.7 I, p=0.03$ & 1.8 & 0.07 & 2.6 & 0.01 & 0.2 & 0.86 \\
\hline Hyperresponsive & $1.4 \pm 0.4$ & $1.4 \pm 0.4$ & $1.2 \pm 0.2$ & $4.38, p=0.02$ & 0.1 & 0.91 & 2.8 & 0.01 & 2.3 & 0.03 \\
\hline Sensory seeking & $2.1 \pm 0.7$ & $1.8 \pm 0.6$ & $1.6 \pm 0.4$ & $8.52, p=0.001$ & 1.4 & 0.18 & 4.1 & 0.001 & 1.9 & 0.07 \\
\hline
\end{tabular}

ASD: autism spectrum disorder; DD: developmental delay; TD: typical development; ANOVA: analysis of variance.

aFour participants in the DD group had missing scores on sensory measures.

procedures performed in studies involving human participants were in accordance with the ethical standards of the institutional and/or national research committee and with the 1964 Declaration of Helsinki and its later amendments or comparable ethical standards. All guardians of participants provided written informed consent, and participants gave written assent if applicable. Families received small monetary incentives and travel reimbursement.

\section{Clinical and behavioral measures}

Participants were administered a standardized cognitive assessment based on their age and developmental level, as per the following protocol. First, an attempt was made to administer the Stanford-Binet Intelligence Scales (Nonverbal), Fifth Edition (Roid, 2003). This effort was successful for more than $90 \%$ of the children in the sample. Children whose MA and/or communication ability were too low to achieve a basal level on the Stanford-Binet received an alternate test-the Mullen Scales of Early Learning (Visual Reception; Mullen, 1995). There were no significant between-group differences in the type of nonverbal IQ (NVIQ) test used ( $p>0.20$ for each comparison). A subset of children $(n=19)$ received both the Stanford-Binet and the Mullen; the correlation between the two tests was $0.87(p<0.001)$, which demonstrates that the overall assessment procedure was able to reliably capture inter-individual variation in MA and NVIQ. Based on the resulting scores, MA equivalents were calculated and entered as covariates in analyses to adjust for betweengroup differences in developmental level.

Two observational measures of sensory responsiveness were collected: the Tactile Defensiveness and Discrimination Test-Revised (TDDT-R; Baranek \& Berkson, 1994) and the Sensory Processing Assessment for Young Children (SPA; Baranek, 1999). The use of observational assessments was incorporated to enhance measurement objectivity, with the use of two such measures enabling a more reliable overall index of the sensory constructs. The TDDT-R, although designed to measure primarily tactile experiences, includes items that reflect a pan-modal conceptualization of sensory features. These items include toys and stimuli with auditory, tactile, and visual properties (e.g. fuzzy puppet, colorful vibrating toy). Scores are obtained by recording and summing children's observed behaviors, which can range from active engagement to avoidance and aversive responses. The TDDT-R takes $15-20 \mathrm{~min}$ to administer and has been validated for use with children aged 3-12 years (Baranek \& Berkson, 1994; Baranek et al., 1997). The SPA is a 20-min play-based assessment that focuses on auditory, tactile, and visual responding during exposure to novel sensory-rich toys (e.g. neon slinky, glitter musical globe, and spinning fan) or to other types of unexpected stimuli such as a sound stick, air puff, or flashing light (Baranek, 1999; Baranek et al., 2007). Children's behavioral responses are rated on dimensions such as sensory defensiveness (e.g. covering ears following application of auditory stimuli), approach versus avoidance, or orienting in relation to presentation of unexpected novel stimuli. Although the SPA was initially developed for children aged 6 years or under, it has been used successfully in measuring children with ASD or DD aged up to 12 years (Kirby et al., 2015).

Items from the aforementioned two instruments were used to derive summary scores for each of the three sensory constructs of interest (hyperresponsiveness, hyporesponsiveness, and seeking) via a combinatorial procedure that involved: (a) based on previous confirmatory factor analyses, grouping items according to the three sensory features; (b) to enable compatibility, adjusting ranges and valences of all items to fit a 5-point scale, with larger scores indicating greater sensory symptoms; and (c) calculating the mean score across items for each sensory feature (Watson et al., 2011). Mean values and group differences for the three sensory constructs are reported in Table 2. Analyses of variance and least significant difference (LSD) multiple comparison tests indicated that: (a) for each sensory feature, a significant overall difference was present among the three means; and (b) in general, sensory scores tended to be highest for the ASD group, followed by the DD and TD groups.

\section{Experimental procedure}

Experimental procedures were conducted in a university laboratory setting. Both early sensory (P1 and N2) and higher-order attentional (P3a) ERP data were obtained via a 
passive auditory oddball paradigm. The passive paradigm, in which no intentional response to the stimulus is required, was applied because of its suitability for young children as well as children with cognitive impairments. The auditory stimuli consisted of tones or unusual sounds, as opposed to social or speech-related sounds. Although the balance of evidence indicates that processing difficulties in ASD tend to be more severe during exposure to socially relevant sounds (e.g. Gervais et al., 2004; Lepisto et al., 2005), the frequent finding of atypical responses to non-speech stimuli in ASD underscores the presence of general processing considerations that extend beyond, but likely contribute to, dysfunctional higher-order deficits including social cognition (O'Connor \& Kirk, 2008). Therefore, we chose to use non-social stimuli as the focus of this initial study examining ASD versus DD differences.

Children were fitted with a 20-electrode Electro Cap (Electro-Cap International, Inc., Eaton, OH, USA), with 11 of the electrodes (F3, Fz, F4, C3, Cz, C4, P3, Pz, P4, T7, and T8) used for recording EEGs. The EEG was acquired with a Neuroscan 4.3 (Neurosoft, Inc., Sterling, VA, USA) system. The right mastoid served as the reference ${ }^{2}$ and $\mathrm{AFz}$ as the ground. EEG data were amplified, bandpass filtered $(0.15-70 \mathrm{~Hz})$, and digitized at $500 \mathrm{~Hz}$. Four tin electrodes placed at the outer canthi of both eyes and above and below the right eye measured vertical and horizontal electro-oculogram (VEOG and HEOG).

During testing, children watched a self-chosen video with low sound $(<60 \mathrm{~dB}$ sound pressure level (SPL)) while tones were randomly presented through speakers. Use of a video with low sound enabled children to remain vigilant and still for acceptably long periods of time, which facilitated the ability to obtain clean ERP data (e.g. Bellis et al., 2000; Todd et al., 2001; Winkler et al., 2003). Furthermore, by directing participants' attention away from the target stimuli, this procedure enabled us to assess both conscious and unconscious deviance detection processing (Näätänen, 2000). Because children with ASD often do not tolerate wearing anything inside the ear, we opted for presenting the sounds over external speakers and did not use in-ear headphones. The video speakers were placed to the left and right of the video screen, spaced $60 \mathrm{~cm}$ apart, at approximately $80 \mathrm{~cm}$ from the child's head. Children were instructed to watch the video and to ignore the sounds. All sounds were presented with an average of $80 \mathrm{~dB}$ SPL as measured by a digital Sound Level Meter (See Appendix 1 for a more detailed clarification of the experimental procedure.) Auditory stimuli were presented with Presentation 13.4. Stimuli included standard tones ( $200 \mathrm{~ms}$ duration, $1000 \mathrm{~Hz}, 88 \%, 2640$ items), pitch-deviant tones ( $200 \mathrm{~ms}$ duration, $1100 \mathrm{~Hz}, 4 \%, 120$ items), duration-deviant tones $(190 \mathrm{~ms}$ duration, $1000 \mathrm{~Hz}, 4 \%, 120$ items), and novel environmental sounds such as a dog bark ( $200 \mathrm{~ms}$ duration, $4 \%, 120$ items). Sound stimuli were created with rise and fall times of $5 \mathrm{~ms}$, digitized at a rate of
$44.1 \mathrm{kHz}$, and 16-bit resolution. Six semi-randomized sequences of tones were generated, with at least two standard tones following each deviant or novel tone. Each sequence was presented once during the six-run task protocol (5 min each), yielding a total of 500 tones per run. A stimulus onset asynchrony of $600 \mathrm{~ms}$ separated each tone.

\section{EEG data analysis}

The EEG data were analyzed with Neuroscan Edit 4.4 and custom MATLAB (The MathWorks, Inc., Natick, MA, USA) scripts built on the open source EEGLAB (Delorme \& Makeig, 2004) and FieldTrip (Oostenveld et al., 2011) toolboxes. After concatenating all runs together, we manually eliminated large artifacts due to subjects' motion, gross facial movements, or other irregularities. A correction algorithm (Semlitsch et al., 1986) was used to adjust for eye movement artifacts. After applying a bandpass zero-phaseshift digital filter $(1-15 \mathrm{~Hz})$, continuous EEG data from all channels were imported into EEGLAB. These relatively strong filter settings were used to remove low frequency drifts and high frequency noise (due to an increased presence of movement artifacts in EEG data from young children with ASD or DD in comparison to healthy adults). Continuous data were epoched using a $100 \mathrm{~ms}$ prestimulus baseline period and a $500 \mathrm{~ms}$ poststimulus period. Individual epochs were passed through an automatic artifact detection algorithm to remove epochs with EEG activity in excess of -90 or $+90 \mu \mathrm{V}$. Subsequently, epochs containing abnormally distributed data (i.e. joint probability or kurtosis $>5$ standard deviations from expected mean values) were rejected. After pre-processing the data, the mean number of acceptable trials for the four event types were as follows: standard-1685.7 (TD), 1563.2 (ASD), 1642.6 (DD); pitch-deviant—90.9 (TD), 85.1 (ASD), 78.6 (DD); duration-deviant-91.3 (TD), 84.0 (ASD), 78.8 (DD); and novel—90.6 (TD), 85.4 (ASD), 79.4 (DD). In each case, the mean for TD significantly exceeded both the ASD and DD means (for all 8 comparisons, $p<0.05$ ), whereas none of the ASD versus DD comparisons indicated a significant difference (all $4 p$-values $>0.05$ ). All participants had at least 55 accepted trials within each of the four conditions.

Event-related potentials (ERPs) were obtained by averaging the baseline-corrected EEG epochs for each stimulus category and for each participant separately in FieldTrip. The P1, N2, and P3a peaks were first identified by an automatic peak detection procedure. Component amplitudes were subsequently quantified as the mean voltage in a $50 \mathrm{~ms}$ window around each subject's individual peak. The P1 peak detection windows for the standard tones, pitch-deviant tones, and duration-deviant tones ranged from 70 to $180 \mathrm{~ms}$. The $\mathrm{N} 2$ windows for these event types ranged from 150 to $274 \mathrm{~ms}$. The P3a window for the novel sounds ranged from 200 to $400 \mathrm{~ms}$. The algorithm for computing ERP component values reflected 
a compromise between focusing solely on peaks versus calculating the average over an observational window. This procedure is efficient in estimating the true ERP signal, especially given individual subjects' latency variability (Clayson et al., 2013). In cases involving an anomalous peak or no peak at all, this procedure was able to still yield values that were viable estimates of ERP activity in the window of interest. Standard stimuli occurring after a pitch-deviant, duration-deviant, or novel stimulus were excluded when computing the ERPs to the standard stimuli. Due to the typically small amplitude of the ERP responses to standard stimuli, we averaged across all remaining standard stimuli to increase the signal-to-noise ratio of the data.

\section{Analytic strategy}

The first objective of this study was to examine group differences in ERP component amplitudes between the ASD, $\mathrm{DD}$, and TD groups. Group differences were compared separately for each ERP component-condition pair of interest with a three-way (three groups (ASD, DD, and TD) $\times 3$ anterior position (frontal, central, and parietal) $\times 3$ lateral position (left, median, and right) $)^{3}$ repeated-measures multivariate analysis of variance (MANOVA). An identical analysis was performed on the latencies of each peak.

In recognition of central auditory maturational changes during childhood (Bishop et al., 2011; Čeponienè et al., 2002; Wunderlich \& Cone-Wesson, 2006), our sampling procedure was designed to minimize between-group differences in age. Although the ASD, DD, and TD participants did not differ significantly in chronological age, this equivalence led to between-group differences in MA (i.e. in connection with group differences in IQ- see Table 1). Therefore, using a strategy that has been successfully employed in previous studies comparing children with versus without ASD (Klusek et al., 2014; McCormick et al., 2016), we statistically adjusted for MA by including it as a covariate in alternate versions of each of the aforementioned analyses.

The second objective of this study was to examine relations between ERP components and clinical measures of sensory response patterns. For this analysis, we combined the ASD and DD groups (and included Group as a covariate), but as in previous efforts (e.g. Donkers et al., 2015) excluded TD children because of (a) their low sensory scores with little variability, (b) the absence of clinically relevant sensory response patterns in this group, (c) the sufficient range in sensory scores among the two remaining groups, and (d) the theoretical ambiguity that would result from analyzing a mixture of typically and atypically developing children. Based on our prior work (Donkers et al., 2015), for this analysis we reduced the dimensionality of the ERP data by creating a composite score formed by averaging the amplitudes from the three central electrodes (C3, $\mathrm{Cz}$, and $\mathrm{C} 4$ ), because all ERP components had largest amplitudes for this position. The analysis consisted of a regression model for each of the three sensory outcomes, with three ERP component predictors (P1, N2, and P3a), and Group and MA entered as covariates. Analysis consisted of two levels. First, a model was run that included all possible two-way interactions between the three ERP components. As a second step, each model was then trimmed by removing all non-significant interaction terms.

Significance tests were two-tailed and were individually conducted at the 0.05 alpha level due to the limited number of theoretically predicted, a priori hypothesis tests (Armstrong, 2014). All statistical analyses were performed using SAS (SAS Institute, Inc., Cary, NC, USA).

\section{Results}

\section{Group differences in ERP}

Figures 1 to 4 present the grand average for standard, duration-deviant, pitch-deviant, and novel tones for the three groups. Table 3 presents the ERP component means, averaged across all electrodes, for each group within each experimental condition. Table 3 additionally summarizes the MANOVA results for group effects. Findings that bear on the study hypotheses are noted below, along with outcomes for the Anterior and Lateral position factors. Appendix 2 presents the ERP component means by group for each of the nine positional electrode locations, and Appendix 3 contains the mean latencies by group for each experimental condition.

\section{Standard tones: amplitudes}

$P I$ results. There was no significant effect of Group on the $\mathrm{P} 1$ amplitude in response to standard tones $(p=0.2)$, nor was there an effect of MA $(p=0.6)$. A pairwise test revealed a marginally significant trend for reduced P1 amplitudes for children with ASD relative to TD children $(F(1,65)=3.2, p=0.08$; corrected: $F(1,63))$ although this comparison was exploratory given the non-significant overall Group effect. There was a main effect of anterior position on the $\mathrm{P} 1$ amplitude $(F(2,158)=24.0$, $p<0.0001$ ), such that parietal electrodes had the lowest amplitudes across groups. The main effect for lateral position was non-significant $(p=0.96)$, and there were no significant two- or three-way interactions $(p>0.25$ for all), reflecting similar effects of electrode location across groups.

N2 results. There was a main effect of Group on the $\mathrm{N} 2$ amplitude in response to standard tones $(F(2,81)=3.6$, $p=0.03$ ), although this effect was reduced when controlling 


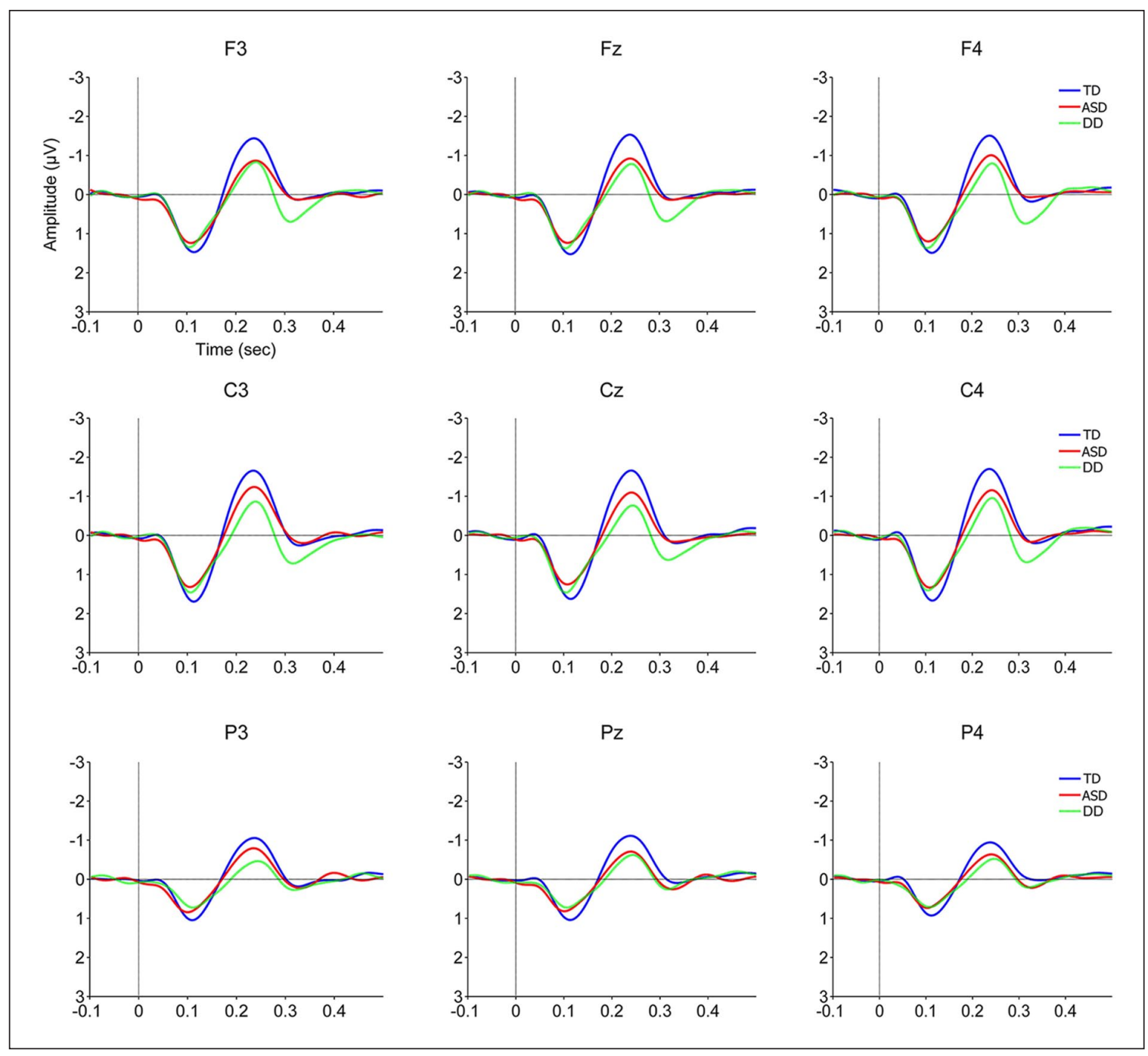

Figure I. Grand averaged ERPs to standard stimuli. Time is in seconds. Time $=0$ indicates stimulus onset. TD: typically developing group; ASD: group with autism; DD: developmentally disabled group.

for MA $(F(2,79)=1.9, p=0.16)$. Follow-up pairwise comparisons showed that this effect was driven by reduced N2 amplitudes for both the ASD group $(F(1,65)=4.0, p=0.05$; corrected: $F(1,63)=2.6, p=0.11)$ and the $\mathrm{DD}$ group $(F(1$, $54)=4.7, p=0.04$; corrected: $F(1,52)=1.4, p=0.24)$ relative to TD. There was no significant effect of MA on N2 amplitudes $(p>0.3)$.

There was a main effect of Anterior position on the N2 amplitude $(F(2,158)=3.6, p=0.03)$, such that amplitudes decreased from central to frontal to parietal electrodes across groups. A non-significant effect was obtained for Lateral position $(F(2,158)=2.4, p=0.10)$, along with a marginally significant interaction effect between Lateral position and $\mathrm{MA}(F(4,158)=2.8, p=0.07)$. There was also a significant three-way interaction between Anterior position, Lateral position, and $\operatorname{Group}(F(8,316)=2.2, p=0.03)$, reflecting that the interactive effects of position varied across groups. There were no other significant two- or three-way interactions ( $p>0.25$ for all).

Deviant tones: amplitudes. There were no significant effects of Group on the amplitudes of either pitch-deviant P1 and $\mathrm{N} 2(p>0.75$ for both) or duration-deviant P1 and N2 $(p>0.5$ for both). There was a significant effect of MA on pitch-deviant $\mathrm{N} 2(F(1,78)=3.9, p=0.05)$, but not on any of the remaining deviant components $(p>0.3$ for all). Apart from an interaction between Anterior position and Group on the duration-deviant P1 $(F(4,158)=2.4, p=0.05)$ and a three-way interaction between Anterior position, Lateral position, and Group for the pitch-deviant N2 $(F(8$, $312)=2.0, p=0.04)$, there were no significant two- or three-way interactions between electrode location and Group for the deviant tones. This suggests similar effects of electrode location across groups. Because there were no 


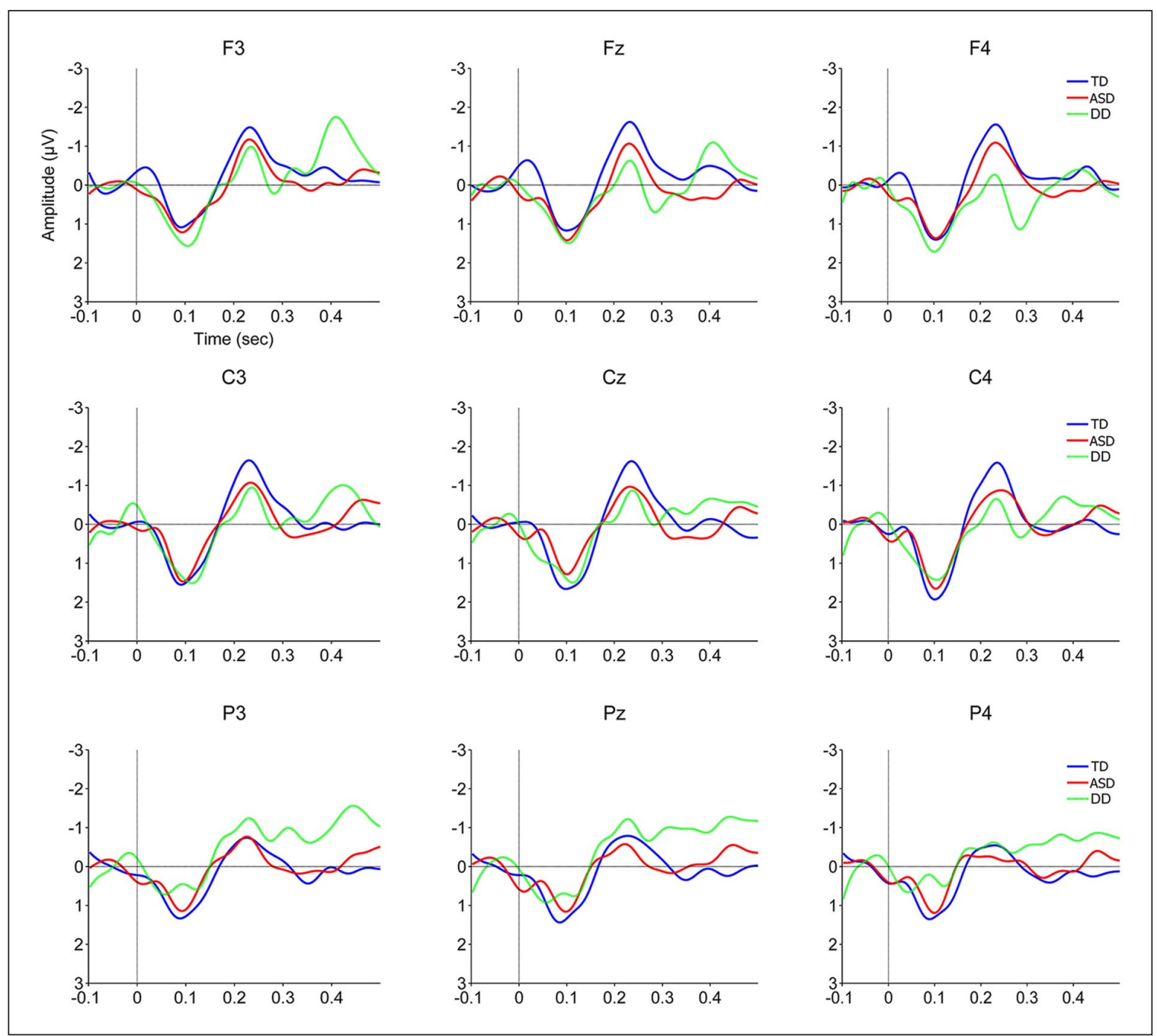

Figure 2. Grand averaged ERPs to duration-deviant stimuli. Time is in seconds. Time $=0$ indicates stimulus onset. TD: typically developing group; ASD: group with autism; DD: developmentally disabled group.

meaningful group effects for the P1 and N2 components for pitch-deviant or duration-deviant stimuli, they were excluded from all further analyses.

Novel sounds: amplitudes. There was a main effect of Group on the P3a amplitude for novel tones $(F(2,80)=3.7$, $p=0.03$ ), which was also present when controlling for MA $(F(2,78)=3.7, p=0.03)$. Follow-up pairwise comparisons showed that this effect was driven by significantly reduced P3a amplitudes in the ASD group relative to both DD $(F(1$, $42)=5.4, p=0.02$; corrected: $F(1,41)=4.4, p=0.04)$ and TD $(F(1,64)=5.8, p=0.02$; corrected: $F(1,62)=6.9$, $p=0.01)$ groups. DD and TD groups did not significantly differ from each other $(p>0.4)$. There was no significant effect for MA $(p=0.16)$.

There was a main effect of Anterior position on the P3a amplitude $(F(2,156)=22.0, p<0.0001)$, such that parietal electrodes had the lowest amplitudes across groups. There was a main effect of Lateral position $(F(2,156)=3.4$, $p=0.04$ ), with highest amplitudes for median electrodes. There was also an interaction of Lateral position and MA $(F(2,156)=3.4, p=0.04)$, and an interaction of Lateral position and Group $(F(4,156)=2.5, p=0.05)$. There was an interaction of Anterior and Lateral positions $(F(4$, $312)=3.1, p=0.02$ ). There were no other significant twoor three-way interactions ( $p>0.3$ for all).

Latency. We conducted an exploratory examination of group differences in ERP latency. Separate Group $\times$ Anterior position $\times$ Lateral position MANOVAs were conducted for each ERP component within each auditory stimulus condition. There was a significant effect of Group on standard P1 latencies $(F(2,79)=3.2, p=0.05)$, such that the DD group had shorter latencies than the TD group $(F(1,52)=6.6, p=0.01)$. In addition, children with higher MA had shorter standard P1 latencies $(F(1,79)=18.2$, 


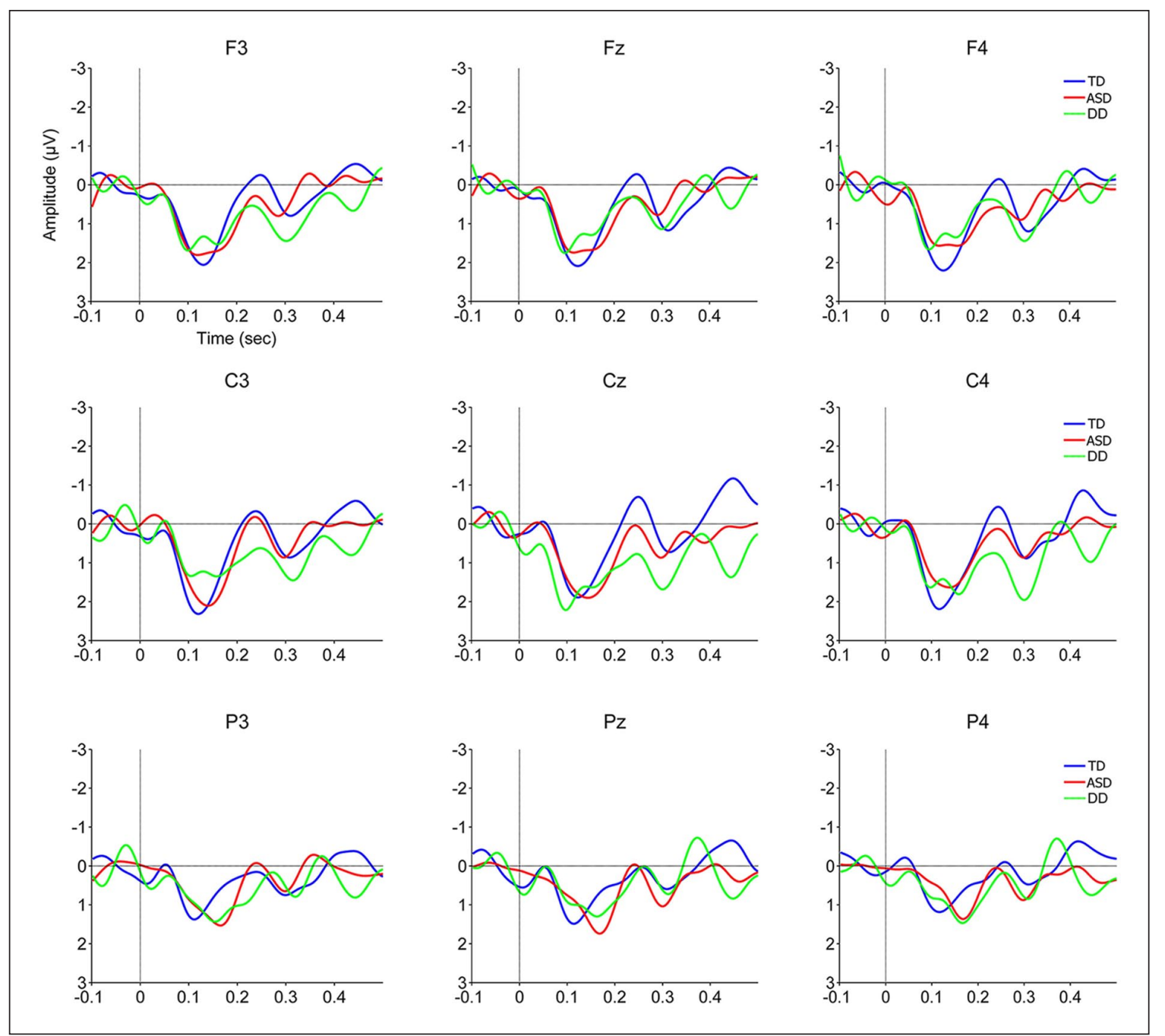

Figure 3. Grand averaged ERPs to pitch-deviant stimuli. Time is in seconds. Time $=0$ indicates stimulus onset. TD: typically developing group; ASD: group with autism; DD: developmentally disabled group.

$p<0.0001)$. There were no effects of Group or MA on the latencies for standard N2, novel P3a, or any of the pitchdeviant components ( $p>0.2$ for all).

\section{Association between ERP amplitudes and sensory features}

Table 4 summarizes the results of regression models designed to predict sensory features in the combined ASD and DD group. Hypothesis-relevant outcomes are described subsequently.

Sensory hyporesponsiveness. The full model including ERP component interactions was significantly predictive of clinically observed Hyporesponsive behaviors $(F(8$, $\left.31)=2.67, p=0.02, R^{2}=0.41\right)$. There were significant effects of MA and Group, and marginally significant effects for P1 and P3a. When the model was trimmed of all non-significant interactions, it remained predictive $(F(5$, $34)=3.77, p=0.01, R^{2}=0.36$ ). Again, significant effects were found for MA and Group, with marginally significant effects for N2 and P3a. Children with higher MA had less severe Hyporesponsive behaviors. ASD children had more Hyporesponsive behaviors than did DD children. A blunted $\mathrm{N} 2$ response predicted more severe behaviors, as did a blunted $\mathrm{P} 3 \mathrm{a}$ response.

Sensory hyperresponsiveness. There was no evidence that the set of ERP predictors and covariates was related to Hyperresponsive behaviors in models either with $(p=0.4)$ or without $(p=0.5)$ interaction terms.

Sensory seeking. The full model with interactions between electrodes significantly predicted Seeking behaviors $(F(8$, $31)=3.26, p=0.008$, adjusted $R^{2}=0.46$ ). Significant effects were found for MA, Group, and the P1 $\times \mathrm{N} 2$ interaction 


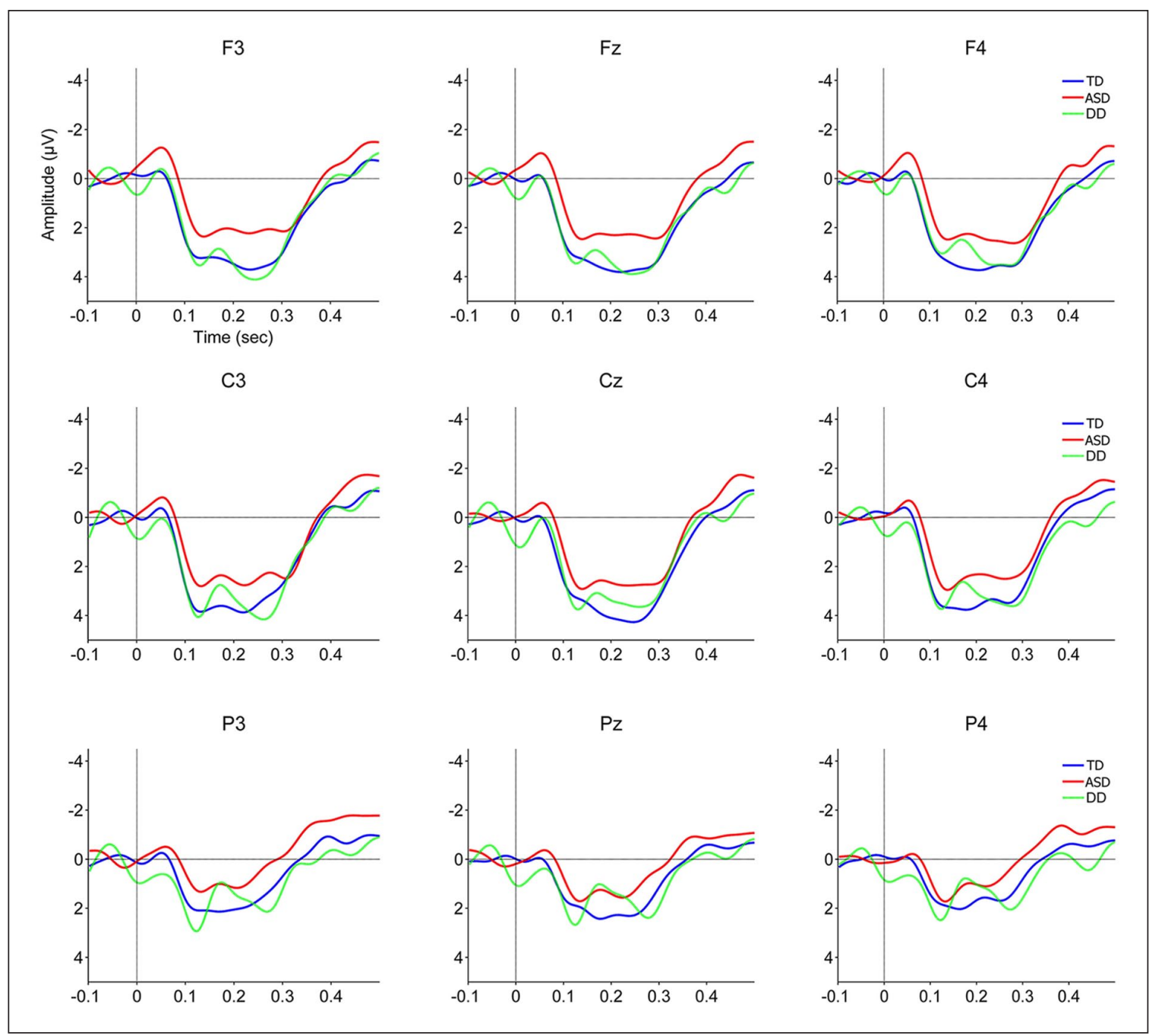

Figure 4. Grand averaged ERPs to novel stimuli. Time is in seconds. Time $=0$ indicates stimulus onset. TD: typically developing group; ASD: group with autism; DD: developmentally disabled group.

term. A trimmed model that excluded all non-significant interactions continued to explain variation in the Seeking behaviors $\left(F(6,33)=4.08, p=0.004\right.$, adjusted $\left.R^{2}=0.43\right)$, with significant effects for MA, $\mathrm{P} 1 \times \mathrm{N} 2$, and $\mathrm{P} 3 \mathrm{a}$, and a marginal effect of Group. The $\mathrm{P} 1 \times \mathrm{N} 2$ interaction reflected that weak $\mathrm{N} 2$ responses were associated with more severe Seeking behaviors for weaker but not stronger amplitudes of P1. More blunted P3a responses were associated with more severe Seeking behaviors. Children with higher MA scores had less severe seeking behaviors. The effect of Group indicated that children with ASD had more seeking behaviors than did DD children.

\section{Discussion}

We found evidence for blunting of early sensory, N2 responses to standard tones among both children with ASD and DD relative to TD peers, an outcome which suggests that prior findings of attenuated early sensory responsivity (e.g. Bruneau et al., 1999; Donkers et al., 2015) may not be specific to children with ASD. In contrast, attention-orienting P3a responses to novel sounds were disrupted in ASD relative to both $\mathrm{DD}$ and TD children. This finding expands on previous results of smaller P3a responses in ASD (e.g. Donkers et al., 2015; Kemner et al., 1995) by establishing that this type of deficit does not stem merely from general DD. This conclusion is buttressed by prior research showing the absence of reduction in $\mathrm{P} 3 \mathrm{a}$ amplitude among young individuals with Down syndrome (Seidl et al., 1997). Our overall pattern of findings suggests that ERP indices of higher-order attentional disruptions are more specific to ASD, while ERP indices of obligatory, lower-order early sensory processing disruptions may present in a wider range of children with DD, including those with ASD.

Associations were also found between ERP components and sensory features. First, marginally significant effects 
Table 3. Mean \pm SD ERP amplitudes (averaged across electrodes) and statistical test results for group differences.

\begin{tabular}{|c|c|c|c|c|c|}
\hline & $\begin{array}{l}\text { ASD } \\
(n=28)\end{array}$ & $\begin{array}{l}\text { DD } \\
(n=17)\end{array}$ & $\begin{array}{l}\text { TD } \\
(n=39)\end{array}$ & $\begin{array}{l}\text { Group effect: unadjusted } \\
\text { MANOVA }^{a}\end{array}$ & $\begin{array}{l}\text { Group effect: adjusted } \\
\text { MANOVA }^{b}\end{array}$ \\
\hline \multicolumn{6}{|c|}{ Standard } \\
\hline $\mathrm{PI}$ & $\mathrm{I} . \mathrm{I} \pm 0.7$ & $1.3 \pm 0.8$ & $1.4 \pm 0.7$ & $F(2,8 I)=1.46, p=0.24$ & $F(2,79)=1.52, p=0.23$ \\
\hline N2 & $-0.9 \pm 0.8$ & $-0.7 \pm 1.0$ & $-1.4 \pm 1.2$ & $\begin{array}{l}F(2,8 I)=3.62, p=0.03 \\
(A S D \text { vs TD, DD vs TD) }\end{array}$ & $F(2,79)=1.90, p=0.16$ \\
\hline \multicolumn{6}{|c|}{ Pitch deviant } \\
\hline $\mathrm{PI}$ & $2.3 \pm 2.0$ & $2.4 \pm 2.3$ & $2.3 \pm 1.8$ & $F(2,80)=0.01, p=0.99$ & $F(2,78)=0.02, p=0.98$ \\
\hline N2 & $-0.6 \pm 1.7$ & $-0.6 \pm 2.1$ & $-0.7 \pm 1.9$ & $F(2,80)=0.06, p=0.94$ & $F(2,78)=0.22, p=0.80$ \\
\hline \multicolumn{6}{|c|}{ Duration deviant } \\
\hline $\mathrm{PI}$ & $1.8 \pm 1.4$ & $1.7 \pm 1.9$ & $1.8 \pm 1.5$ & $F(2,8 I)=0.05, p=0.95$ & $F(2,79)=0.19, p=0.83$ \\
\hline N2 & $-1.5 \pm 1.9$ & $-1.5 \pm 2.5$ & $-1.8 \pm 1.7$ & $F(2,8 I)=0.38, p=0.68$ & $F(2,79)=0.46, p=0.63$ \\
\hline \multicolumn{6}{|l|}{ Novel } \\
\hline P3a & $3.0 \pm 2.0$ & $4.5 \pm 2.9$ & $4.0 \pm 2.1$ & $\begin{array}{l}F(2,80)=3.73, p=0.03 \\
(A S D \text { vs } D D, A S D \text { vs TD) }\end{array}$ & $\begin{array}{l}F(2,78)=3.72, p=0.03 \\
(A S D \text { vs } D D, A S D \text { vs TD) }\end{array}$ \\
\hline
\end{tabular}

ASD: autism spectrum disorder; DD: developmental delay; TD: typical development; MANOVA: multivariate analysis of variance.

aMANOVA based on group $\times$ anterior position $\times$ lateral position, unadjusted for mental age.

bMANOVA based on group $\times$ anterior position $\times$ lateral position, co-varying for mental age.

cPairwise comparisons significant beyond the 0.05 level are noted in brackets.

for N2 and P3a were found in predicting Hyporesponsiveness, such that more severe Hyporesponsive behaviors were associated with lower ERP amplitudes. Second, Sensory Seeking behaviors were predicted by a $\mathrm{P} 1 \times \mathrm{N} 2$ interaction (with the joint presence of weak ERP responses predictive of greater Seeking behavior) and a blunted P3a component. Taken together, our results suggest that Hyporesponsive and Sensory Seeking behaviors are linked to neural processes at both the sensory and attentional levels. Therefore, and especially in the ASD group (which evidenced greater attenuation of P3a as well as the highest mean levels of Hyporesponsiveness and Seeking), both bottom-up and top-down mechanisms could contribute to the expression of aberrant sensory behaviors.

The neural disruption in attentional processing that is specific to ASD may potentially play a contributory role within a wider chain of abnormal responding that culminates in overt symptoms. For example, participation in daily activities is difficult for children with sensory challenges (Bagby et al., 2012; Little et al., 2015; Reynolds et al., 2011; Schaaf et al., 2011). If attentional processes are disrupted at the neural level, children may fail to orient sufficiently to relevant stimuli in their environment, impairing their daily engagement, social learning, and adaptive behavior. Such effects may be strongly mediated by sensory features. Likewise, children who exhibit blunting of the P1 $\times$ N2 interaction or P3a attentional response may be more likely to engage in abnormal seeking behaviors in an effort to compensate for insufficient levels of experienced sensation. In addition, the lack of normal involvement with environmental stimuli that is associated with severe hyporesponsiveness may in part be a reflection of blunted N2 and $\mathrm{P} 3 \mathrm{a}$ responses to sensory stimuli in the environment.
A noteworthy proportion of children with ASD scored well within the normal range of ERP outcomes for TD children. For example, the median P3a amplitude (averaged across electrodes) of the children with ASD exceeded the Q1 value (i.e. 25th percentile) for the TD group. This observation is congruent with the heterogeneous nature of autism and suggests that early sensory deficits are not a necessary link in the path that leads to more widespread abnormalities in ASD. Given the complex, interlocked network of genetic, neurophysiological, environmental, and behavioral disruptions implicated in this disorder (Pelphrey et al., 2011), there is no compelling reason why abnormal developmental outcomes must uniformly start with or even directly involve early sensory (or early attentional) processing, although certainly early sensory disruptions may have downstream consequences when present. Relatedly, the results of prior research suggest the possibility of top-down influences on early sensory responding in ASD (e.g. Pellicano \& Burr, 2012; Sable et al., 2004; Whitehouse \& Bishop, 2008), which may vary on an inter-individual basis and may be reinforced by attentional factors associated with blunting of the $\mathrm{P} 3 \mathrm{a}$ response. Further research is needed to better understand the complex interplay between sensory and attentional factors that affect auditory information processing in children with ASD.

\section{Clinical relevance}

The outcomes of this study are consistent with a couple of overarching intervention principles. First, along with prior recommendations, the results support the call for early detection and intervention to reduce the development of abnormalities in nascent neural circuitry (Dawson, 2008). 
Table 4. Associations between ERP composites and observed sensory behaviors.

\begin{tabular}{|c|c|c|c|c|}
\hline & \multicolumn{2}{|l|}{ Full model } & \multicolumn{2}{|c|}{ Trimmed model } \\
\hline & Est (SE) & $p$ & Est (SE) & $p$ \\
\hline \multicolumn{5}{|c|}{ Hyporesponsiveness } \\
\hline Intercept & $3.69(0.83)$ & 0.0001 & $2.74(0.4)$ & $<0.0001$ \\
\hline MA & $-0.01(0.00)$ & 0.02 & $-0.01(0.00)$ & 0.008 \\
\hline ASD vs DD & $0.72(0.25)$ & 0.007 & $0.73(0.24)$ & 0.005 \\
\hline $\mathrm{PI}$ & $-0.78(0.47)$ & 0.11 & $-0.15(0.17)$ & 0.39 \\
\hline N2 & $0.4 I(0.34)$ & 0.24 & $0.22(0.12)$ & 0.08 \\
\hline $\mathrm{P} 3 \mathrm{a}$ & $-0.34(0.19)$ & 0.08 & $-0.09(0.05)$ & 0.10 \\
\hline $\mathrm{PI} \times \mathrm{N} 2$ & $-0.01(0.15)$ & 0.93 & & \\
\hline $\mathrm{PI} \times \mathrm{P} 3 \mathrm{a}$ & $0.16(0.11)$ & 0.16 & & \\
\hline $\mathrm{N} 2 \times \mathrm{P} 3 \mathrm{a}$ & $-0.03(0.07)$ & 0.63 & & \\
\hline$F(\mathrm{df})$ & $2.67(8,31)$ & 0.02 & $3.77(5,34)$ & 0.008 \\
\hline$R^{2}$ & 0.41 & & 0.36 & \\
\hline \multicolumn{5}{|c|}{ Hyperresponsiveness } \\
\hline Intercept & I.4I (0.45) & 0.004 & $1.67(0.22)$ & $<0.0001$ \\
\hline MA & $0.00(0.00)$ & 0.06 & $0.00(0.00)$ & 0.04 \\
\hline ASD vs DD & $0.13(0.13)$ & 0.34 & $0.10(0.13)$ & 0.46 \\
\hline $\mathrm{PI}$ & $0.02(0.25)$ & 0.95 & $-0.08(0.09)$ & 0.41 \\
\hline N2 & $-0.25(0.18)$ & 0.18 & $0.00(0.07)$ & 0.96 \\
\hline $\mathrm{P} 3 \mathrm{a}$ & $0.02(0.10)$ & 0.84 & $0.01(0.03)$ & 0.82 \\
\hline $\mathrm{PI} \times \mathrm{N} 2$ & $0.03(0.08)$ & 0.73 & . & . \\
\hline $\mathrm{PI} \times \mathrm{P} 3 \mathrm{a}$ & $0.00(0.06)$ & 0.94 & . & . \\
\hline $\mathrm{N} 2 \times \mathrm{P} 3 \mathrm{a}$ & $0.04(0.04)$ & 0.31 & . & . \\
\hline$F(\mathrm{df})$ & $1.02(8,31)$ & 0.44 & $0.98(5,34)$ & 0.45 \\
\hline$R^{2}$ & 0.21 & & 0.13 & \\
\hline \multicolumn{5}{|l|}{ Sensory seeking } \\
\hline Intercept & $2.52(0.74)$ & 0.002 & $2.92(0.46)$ & $<0.0001$ \\
\hline MA & $-0.01(0.00)$ & 0.01 & $-0.01(0.00)$ & 0.008 \\
\hline ASD vs DD & $0.46(0.22)$ & 0.04 & $0.4 \mid(0.2 I)$ & 0.06 \\
\hline $\mathrm{PI}$ & $0.00(0.4 I)$ & 0.99 & $-0.14(0.23)$ & 0.54 \\
\hline N2 & $0.08(0.30)$ & 0.80 & $0.32(0.22)$ & 0.15 \\
\hline $\mathrm{P} 3 \mathrm{a}$ & $0.00(0.17)$ & 1.00 & $-0.11(0.05)$ & 0.02 \\
\hline $\mathrm{PI} \times \mathrm{N} 2$ & $-0.32(0.14)$ & 0.02 & $-0.23(0.12)$ & 0.05 \\
\hline $\mathrm{PI} \times \mathrm{P} 3 \mathrm{a}$ & $-0.06(0.1)$ & 0.55 & . & . \\
\hline $\mathrm{N} 2 \times \mathrm{P} 3 \mathrm{a}$ & $0.08(0.06)$ & 0.21 & . & . \\
\hline$F(\mathrm{df})$ & $3.26(8,31)$ & 0.008 & $4.08(6,33)$ & 0.004 \\
\hline$R^{2}$ & 0.46 & & 0.43 & \\
\hline
\end{tabular}

SE: standard error; MA: mental age; ASD: autism spectrum disorder; DD: developmental delay.

Toward this end, detailed information on the pattern of ERP attenuation can contribute to the identification of developmental endophenotypes (i.e. pre-behavioral markers-such as neuroanatomical, neuropsychological, or biochemical characteristics - that predict the later appearance of overt abnormalities). Such knowledge is important because it can bolster efforts at prompt diagnosis, support interventions that may mitigate some of the downstream consequences on development, and possibly facilitate prevention of some of the core features of ASD (Jeste \& Nelson, 2009). Second, the presence of significant interindividual variation in ERP responses of children with ASD suggests the possibility of two-fold intervention strategies that attempt to build on the existing strengths as well as remedy weaknesses.

At a more specific level, the study results underscore the value of focusing on both sensory and attentional processing in ASD as a means of supporting optimal engagement in meaningful activities or improving communication. Accordingly, there is a need for solutions that heighten the salience of important social and non-social sensory stimuli to accomplish treatment goals. Such applications might entail the use of learning paradigms involving graduated exposure to increasingly amplified stimuli so as to reduce attenuated responding without incurring hyperresponsive reactions. Furthermore, the study findings have potential 
clinical implications for improving attentional resources in children with specific patterns of sensory response. Such strategies include: (a) for children with clinically observed sensory Hyporesponsiveness, elevating the physical prominence of sensory stimuli concomitantly with directing attention to social stimuli; and (b) for children who are overly focused on sensory preoccupations or seeking behaviors, using altered modes of stimulus presentation to shift attention to more meaningful or adaptive sensory experiences.

However, we view the aforementioned clinical extrapolations as tentative for at least two reasons. First, up to this point it has been difficult to translate research on auditory ERPs into practice due to considerations such as inconsistent results across studies, use of different stimuli and experimental paradigms, and a lack of age-based norms (Tome et al., 2015). A second reason for caution pertains to the relatively distal connection between auditory ERPs and behaviorally based treatment goals. This latter caveat is underscored by theoretical accounts that emphasize the influence of complexly interrelated brain mechanisms, some compensatory, which develop as accommodations to neurally based constraints associated with ASD (Belmonte et al., 2004; Pelphrey et al., 2011). It is possible that such processes could disrupt the presumed causal chain that extends from early ERPs to intended intervention outcomes such as decreases in core symptoms.

\section{Limitations}

One study limitation pertains to distinctiveness of the deviant tones. For both the pitch- and duration-deviant conditions, the target tones differed from the standard tones by only $5 \%-10 \%$ on the manipulated dimensions (1100 vs $1000 \mathrm{~Hz}$ and 190 vs $200 \mathrm{~ms}$ duration). Use of somewhat more atypical deviant stimuli might have led to between-group differences in ERP that were more comparable to those obtained for novel sounds.

In addition, it is possible that children with ASD, relative to either children in the TD or DD groups, were more highly absorbed in watching the video. The use of a video with low sound may have contributed to dampened ERP responses in this group. However, this possibility does not necessarily reduce the importance of the study findings, as various distractors are commonly present in naturalistic settings and this finding may provide valuable information for researchers and clinicians working with these children. However, further research on the effects of competing background environmental stimuli on sound processing in ASD is warranted.

The small sample size of children with DD, which reflected the commonly experienced difficulty in recruiting such participants in studies that examine sensory features in ASD, constitutes a third limitation. However, statistically significant findings in the face of small samples are still indicative of relationship, as they furnish a conservative test that requires a relatively larger effect size to reject the null hypothesis. Although additional studies with larger samples are warranted, the present results nonetheless lay important groundwork for understanding EEG response patterns in children with ASD.

A further limitation is that differential attrition rates may have reduced the comparative degree of ERP attenuation in children with ASD. Attrition was highest in the ASD group (38\% vs $19 \%$ for DD and $15 \%$ for TD), largely due to increased discomfort with the EEG procedure. Given the association between sensory features and diminished ERP responses, the between-group comparisons are likely to have disproportionately excluded children with ASD who are at the highest risk for auditory deficit, particularly those with high levels of hyperresponsiveness. Reduced study enrollment among children with ASD with lower MA and/or communication ability may have also contributed to this effect.

\section{Conclusion}

This study expands and clarifies previous findings by demonstrating that children with ASD have unique disruptions in neural attentional responses to auditory stimuli, while providing evidence that children with both ASD and more general DD have disruptions in early sensory neural responses. By isolating both shared and unique neural processing impairments, this study indicates that, when characterizing a cohort of children with ASD, it is important to include comparisons to both DD and TD peers in order to distinguish between atypicalities that are unique to ASD and those that are present across children with developmental disabilities.

This study further demonstrated that neural disruptions are related to sensory response patterns across ASD and DD groups. Various strands of evidence suggested that blunted auditory ERPs are associated with hyporesponsive or sensory seeking behaviors, which underscores the potential value of identifying neural markers of the clinically defined sensory patterns. Such markers may be possible to identify early in life (e.g. Elsabbagh et al., 2013; Freuler et al., 2012), thereby supporting timely prevention, diagnosis, or treatment. This work therefore highlights the importance of understanding the neural basis of sensory and attention processing in autism, and how the interaction of these two constructs may underscore atypical sensory response patterns observed in this population.

\section{Acknowledgements}

We thank the families whose participation made this study possible and the staff who collected the data. We acknowledge the Neurodevelopmental Disorders Research Center Autism Subject Registry at The University of North Carolina at Chapel Hill. We also acknowledge the contributions of Katherine Cleary in data 
collection, Anna Evans in data collection and preliminary analysis, John Bulluck in database management, John Sideris in data management and manuscript preparation, Jeanne Lovmo in assistance with subject recruitment and clinical testing, and Jeanine Blanchard and Sarah Gleason Wohlgemuth in manuscript preparation.

\section{Author contributions}

G.T.B. and A.B. designed the study, secured funding, and oversaw the data collection and analysis. S.E.S. conducted statistical analyses in consultation with G.T.B. and A.B., F.C.L.D. contributed to study design, data collection, and data analysis. All five authors contributed to the interpretation of the analysis, writing of the manuscript, and approved the final manuscript.

\section{Declaration of conflicting interests}

The author(s) declared no potential conflicts of interest with respect to the research, authorship, and/or publication of this article.

\section{Funding}

The author(s) disclosed receipt of the following financial support for the research, authorship, and/or publication of this article: This research was supported in part by the Eunice Kennedy Shriver National Institute for Child Health and Human Development (R01-HD042168; T32-HD040127).

\section{ORCID iDs}

Franc CL Donkers iD https://orcid.org/0000-0002-8252-0426 Grace T Baranek iD https://orcid.org/0000-0002-5321-6353

\section{Supplemental material}

Supplemental material for this article is available online.

\section{Notes}

1. In adults, the P1 ERP component in response to simple tones is typically followed by the N1-P2 complex. However, in young children the P1 is followed by one negative peak only. This negativity, described as the N2 in this article, decreases in size from 5 to 10 years of age and becomes expressed primarily as the $\mathrm{N} 1$ in adults.

2. A significant percentage of the participants pulled off the A1 electrode before or during recording. To maximize the final sample, we decided to keep the online reference (right mastoid) as the final reference, as opposed to re-referencing the data to the average of the left and right mastoid (in Appendix 1 and Supplemental Figures A1 to A12 the effect of using a single hemispheric reference vs an averaged hemispheric reference vs a non-mastoid reference is laid out).

3. Note that significant findings regarding the factor Lateral position should be interpreted with caution, as a single mastoid reference could theoretically introduce artificial ERP differences between left and right hemispheres (see also Appendix 1).

\section{References}

American Psychiatric Association. (2013). Diagnostic and statistical manual of mental disorders. https://doi.org/10.1176/ appi.books.9780890425596
Armstrong, R. A. (2014). When to use the Bonferroni correction. Ophthalmic \& Physiological Optics, 34, 502-508. https:// doi.org/10.1111/opo.12131

Ausderau, K., Sideris, J., Furlong, M., Little, L. M., Bulluck, J., \& Baranek, G. T. (2014). National survey of sensory features in children with ASD: Factor structure of the sensory experience questionnaire (3.0). Journal of Autism and Developmental Disorders, 44(4), 915-925. https://doi. org/10.1007/s10803-013-1945-1

Bagby, M. S., Dickie, V. A., \& Baranek, G. T. (2012). How sensory experiences of children with and without autism affect family occupations. American Journal of Occupational Therapy, 66(1), 78-86.

Baranek, G. T. (1999). Sensory processing assessment for young children (SPA). Unpublished manuscript, University of North Carolina at Chapel Hill, Chapel Hill, NC.

Baranek, G. T., \& Berkson, G. (1994). Tactile defensiveness in children with developmental disabilities: Responsiveness and habituation. Journal of Autism and Developmental Disorders, 24(4), 457-471.

Baranek, G. T., Boyd, B., Poe, M., David, F., \& Watson, L. (2007). Hyperresponsive sensory patterns in young children with autism, developmental delay, and typical development. American Journal of Mental Retardation, 112(4), 233-245.

Baranek, G. T., David, F. J., Poe, M. D., Stone, W. L., \& Watson, L. R. (2006). Sensory Experiences Questionnaire: Discriminating sensory features in young children with autism, developmental delays, and typical development. Journal of Child Psychology and Psychiatry, and Allied Disciplines, 47(6), 591-601. https://doi.org/10.1111/j.14697610.2005.01546.x

Baranek, G. T., Foster, L. G., \& Berkson, G. (1997). Tactile defensiveness and stereotyped behaviors. American Journal of Occupational Therapy, 51(2), 91-95.

Bellis, T. J., Nico, T., \& Kraus, N. (2000). Aging affects hemispheric asymmetry in the neural representation of speech sounds. Journal of Neuroscience, 20(2), 791-797.

Belmonte, M. K., Cook, E. H., Anderson, G. M., Rubenstein, J. L. R., Greenough, W. T., Beckel-Mitchener, A., . . . DeLorey, T. M. (2004). Autism as a disorder of neural information processing: Directions for research and targets for therapy. Molecular Psychiatry, 9(7), 646-663.

Ben-Sasson, A., Hen, L., Fluss, R., Cermak, S. A., Engel-Yeger, B., \& Gal, E. (2009). A meta-analysis of sensory modulation symptoms in individuals with autism spectrum disorders. Journal of Autism and Developmental Disorders, 39(1), 1-11. https://doi.org/10.1007/s10803-008-0593-3

Bishop, D. V. M., Anderson, M., Reid, C., \& Fox, A. M. (2011). Auditory development between 7 and 11 years: An eventrelated potential (ERP) study. PLOS ONE, 6(5), Article e18993.

Bomba, M. D., \& Pang, E. W. (2004). Cortical auditory evoked potentials in autism: A review. International Journal of Psychophysiology, 53(3), 161-169. https://doi.org/10.1016/j. ijpsycho.2004.04.001

Bruneau, N., Roux, S., Adrien, J. L., \& Barthélémy, C. (1999). Auditory associative cortex dysfunction in children with autism: Evidence from late auditory evoked potentials (N1 wave-T complex). Clinical Neurophysiology, 110(11), 1927-1934. https://doi.org/10.1016/S1388-2457 (99)00149-2 
Čeponienè, R., Rinne, T., \& Näätänen, R. (2002). Maturation of cortical sound processing as indexed by event-related potentials. Clinical Neurophysiology, 113(6), 870-882.

Clayson, P. E., Baldwin, S. A., \& Larson, M. J. (2013). How does noise affect amplitude and latency measurement of eventrelated potentials? A methodological critique and simulation study. Psychophysiology, 50(2), 174-186.

Dawson, G. (2008). Early behavioral intervention, brain plasticity, and the prevention of autism spectrum disorder. Development and Psychopathology, 20(3), 775-803.

Delorme, A., \& Makeig, S. (2004). EEGLAB: An open source toolbox for analysis of single-trial EEG dynamics including independent component analysis. Journal of Neuroscience Methods, 134(1), 9-21. https://doi.org/10.1016/j.jneumeth.2003.10.009

Donkers, F. C., Schipul, S. E., Baranek, G. T., Cleary, K. M., Willoughby, M. T., Evans, A. M., . . Belger, A. (2015). Attenuated auditory event-related potentials and associations with atypical sensory response patterns in children with autism. Journal of Autism and Developmental Disorders, 45(2), 506-523. https://doi.org/10.1007/s10803013-1948-y

Duffy, F. H., \& Als, H. (2012). A stable pattern of EEG spectral coherence distinguishes children with autism from neuro-typical controls-A large case control study. BMC Medicine, 10(1), 64. https://doi.org/10.1186/1741-7015-1064

Elsabbagh, M., Fernandes, J., Jane Webb, S., Dawson, G., Charman, T., Johnson, M. H., \& British Autism Study of Infant Siblings Team. (2013). Disengagement of visual attention in infancy is associated with emerging autism in toddlerhood. Biological Psychiatry, 74(3), 189-194. https:// doi.org/10.1016/j.biopsych.2012.11.030

Freuler, A., Baranek, G. T., Watson, L. R., Boyd, B. A., \& Bulluck, J. C. (2012). Precursors and trajectories of sensory features: Qualitative analysis of infant home videos. American Journal of Occupational Therapy, 66(5), e81e84. https://doi.org/10.5014/ajot.2012.004465

Gervais, H., Belin, P., Boddaert, N., Leboyer, M., Coez, A., Sfaello, I., . . Zibovicius, M. (2004). Abnormal cortical voice processing in autism. Nature Neuroscience, 7(8), 801-802.

Gotham, K., Pickles, A., \& Lord, C. (2009). Standardizing ADOS scores for a measure of severity in autism spectrum disorders. Journal of Autism and Developmental Disorders, 39(5), 693-705.

Jeste, S. S., \& Nelson, C. A. (2009). Event related potentials in the understanding of autism spectrum disorders: An analytical review. Journal of Autism and Developmental Disorders, 39(3), 495-510. https://doi.org/10.1007/s10803008-0652-9

Kemner, C., Verbaten, M. N., Cuperus, J. M., Camfferman, G., \& van Engeland, H. (1995). Auditory event-related brain potentials in autistic children and three different control groups. Biological Psychiatry, 38(3), 150-165. https://doi. org/10.1016/0006-3223(94)00247-Z

Kirby, A. V., Little, L. M., Schultz, B., \& Baranek, G. T. (2015). Observational characterization of sensory interests, repetitions, and seeking behaviors. American Journal of Occupational Therapy, 69(3), 1-9.
Klusek, J., Martin, G. E., \& Losh, M. (2014). A comparison of pragmatic language in boys with autism and fragile $\mathrm{X}$ syndrome. Journal of Speech, Language, and Hearing Research, 57(5), 1692-1707. https://doi.org/10.1044/2014 JSLHR-L-13-0064

Lane, A. E., Dennis, S. J., \& Geraghty, M. E. (2011). Brief report: Further evidence of sensory subtypes in autism. Journal of Autism and Developmental Disorders, 41(6), 826-831. https://doi.org/10.1007/s10803-010-1103-y

Lepisto, T., Kajala, T., Vanhala, R., Alku, P., Huotilainen, M., \& Naatanen, R. (2005). The discrimination of and orienting to speech and non-speech sounds in children with autism. Brain Research, 1066(1), 147-157.

Liss, M., Saulnier, C., Fein, D., \& Kinsbourne, M. (2006). Sensory and attention abnormalities in autistic spectrum disorders. Autism: The International Journal of Research and Practice, 10(2), 155-172. https://doi. org/10.1177/1362361306062021

Little, L. M., Ausderau, K., Sideris, J., \& Baranek, G. T. (2015). Activity participation and sensory features among children with autism spectrum disorders. Journal of Autism and Developmental Disorders, 45(9), 2981-2990. https://doi. org/10.1007/s10803-015-2460-3

Lord, C., Risi, S., DiLavore, P. S., Shulman, C., Thurm, A., \& Pickles, A. (2006). Autism from 2 to 9 years of age. Archives of General Psychiatry, 63(6), 694-701. https://doi. org/10.1001/archpsyc.63.6.694

Lord, C., Rutter, M., DiLavore, P. C., Risi, S., Gotham, K., \& Bishop, S. L. (2012). Autism Diagnostic Observation Schedule (ADOS-2) (2nd ed.). Western Psychological Services.

Lord, C., Rutter, M., \& Le Couteur, A. (1994). Autism Diagnostic Interview-revised: A revised version of a diagnostic interview for caregivers of individuals with possible pervasive developmental disorders. Journal of Autism and Developmental Disorders, 24(5), 659-685.

Marco, E. J., Hinkley, L. B. N., Hill, S. S., \& Nagarajan, S. S. (2011). Sensory processing in autism: A review of neurophysiologic findings. Pediatric Research, 69(5, Pt. 2), 48R54R. https://doi.org/10.1203/PDR.0b013e3182130c54

McCormick, C., Hepburn, S., Young, G. S., \& Rogers, S. J. (2016). Sensory symptoms in children with autism spectrum disorder, other developmental disorders and typical development: A longitudinal study. Autism, 20(5), 572-579.

Mullen, E. M. (1995). Mullen Scales of early learning (AGS ed.). Western Psychological.

Näätänen, R. (2000). Mismatch negativity (MMN): Perspectives for application. International Journal of Psychophysiology, 37(1), 3-10.

O'Connor, K. (2012). Auditory processing in autism spectrum disorder: A review. Neuroscience and Behavior Reviews, 36, 836-854.

O'Connor, K., \& Kirk, I. (2008). Brief report: Atypical social cognition and social behaviours in autism spectrum disorder: A different way of processing rather than an impairment. Journal of Autism and Developmental Disorders, 38(10), 1989-1997.

O’Donnell, S., Deitz, J., Kartin, D., Nalty, T., \& Dawson, G. (2012). Sensory processing, problem behavior, adaptive behavior, and cognition in preschool children with autism spectrum 
disorders. The American Journal of Occupational Therapy, 66(5), 586-594. https://doi.org/10.5014/ajot.2012.004168

Oostenveld, R., Fries, P., Maris, E., \& Schoffelen, J.-M. (2011). FieldTrip: Open source software for advanced analysis of MEG, EEG, and invasive electrophysiological data. Computational Intelligence and Neuroscience, 2011(2011), 156869. https://doi.org/10.1155/2011/156869

Pellicano, E., \& Burr, D. (2012). When the world becomes 'too real': A Bayesian explanation of autistic perception. Trends in Cognitive Sciences, 16(10), 504-510.

Pelphrey, K. A., Shultz, S., Hudac, C. M., \& Vander Wyk, B. C. (2011). Constraining heterogeneity: The social brain and its development in autism spectrum disorder. Journal of Child Psychology and Psychiatry, 52(6), 631-644.

Reynolds, S., Bendixen, R. M., Lawrence, T., \& Lane, S. J. (2011). A pilot study examining activity participation, sensory responsiveness, and competence in children with high functioning autism spectrum disorder. Journal of Autism and Developmental Disorders, 41(11), 1496-1506. https:// doi.org/10.1007/s10803-010-1173-x

Roid, G. H. (2003). Stanford-Binet Intelligence Scales (SBS) (5th ed.). Riverside Publishing.

Russo, N., Foxe, J. J., Brandwein, A. B., Altschuler, T., Gomes, H., \& Molholm, S. (2010). Multisensory processing in children with autism: High-density electrical mapping of auditory-somatosensory integration. Autism Research, 3(5), 253-267. https://doi.org/10.1002/aur.152

Russo, N., Mottron, L., Burack, J. A., \& Jemel, B. (2012). Parameters of semantic multisensory integration depend on timing and modality order among people on the autism spectrum: Evidence from event-related potentials. Neuropsychologia, 50(9), 2131-2141. https://doi.org/10.1016/j.neuropsychologia.2012.05.003

Sable, J. J., Low, K. A., Maclin, E. L., Fabiani, M., \& Gratton, G. (2004). Latent inhibition mediates N1 attenuation to repeating sounds. Psychophysiology, 41(4), 636-642.

Schaaf, R. C., Toth-Cohen, S., Johnson, S. L., Outten, G., \& Benevidas, T. W. (2011). The everyday routines of families of children with autism: Examining the impact of sensory processing difficulties on the family. Autism, 15(3), 373-389.

Schoen, S., \& Miller, L. (2009). Physiological and behavioral differences in sensory processing: A comparison of children with autism spectrum disorder and sensory modulation disorder. Frontiers in Integrative Neuroscience, 3, Article 29. https://doi.org/10.3389/neuro.07.029.2009

Schopler, E., Reichler, R. J., \& Renner, B. R. (1986). The Childhood Autism Rating Scale (CARS): For diagnostic screening and classification of autism. Irvington.

Seidl, R., Hauser, E., Bernert, G., Marx, M., Freilinger, M., \& Lubec, G. (1997). Auditory evoked potentials in young patients with Down syndrome. Event-related potentials (P3) and histaminergic system. Cognitive Brain Research, 5(4), 301-309.

Semlitsch, H. V., Anderer, P., Schuster, P., \& Presslich, O. (1986). A solution for reliable and valid reduction of ocular artifacts, applied to the P300 ERP. Psychophysiology, 23(6), 695-703.

Todd, J., Michie, P. T., \& Jablensky, A. V. (2001). Do loudness cues contribute to duration mismatch negativity reduction in schizophrenia? NeuroReport, 12(18), 4069-4073.
Tome, D., Barbosa, F., Nowak, K., \& Marques-Teixeira, J. (2015). The development of the N1 and N2 components in auditory oddball paradigms: A systematic review with narrative analysis and suggested normative values. Journal of Neural Transmission, 122(3), 375-391.

Warren, R. M. (1970). Elimination of biases in loudness judgments for tones. Journal of the Acoustical Society of America, 48(6B), 1397-1403.

Warren, R. M. (1973). Quantification of loudness. American Journal of Psychology, 86(4), 807-825.

Watson, L. R., Patten, E., Baranek, G. T., Poe, M., Boyd, B. A., Freuler, A., \& Lorenzi, J. (2011). Differential associations between sensory response patterns and language, social, and communication measures in children with autism or other developmental disabilities. Journal of Speech, Language, and Hearing Research, 54(6), 1562-1576. https://doi. org/10.1044/1092-4388(2011/10-0029)

Whitehouse, A. J., \& Bishop, D. (2008). Do children with autism "switch off" to sounds? An investigation using event-related potentials. Developmental Science, 11(4), 516-524.

Winkler, I., Teder-Sälejärvi, W. A., Horváth, J., Näätänen, R., \& Sussman, E. (2003). Human auditory cortex tracks taskirrelevant sound sources. NeuroReport, 14(16), 2053-2056.

Wunderlich, J. L., \& Cone-Wesson, B. K. (2006). Maturation of CAEP in infants and children: A review. Hearing Research, 212(1-2), 212-223.

\section{Appendix I}

\section{Supplementary information regarding re-referencing and experimental procedure}

Effect of a single hemispheric versus averaged hemispheric versus non-mastoid reference. To show that our results: (a) are not impacted by use of a single hemispheric electrode reference as opposed to an averaged hemispheric reference, but (b) would be impacted by using a non-mastoid reference, we present the data below (see Supplemental Figures A1 to A12) with a left hemisphere reference, a right hemisphere reference, and an averaged left and right hemisphere reference. We recomputed the data using channel P3, channel P4, or the average of these as the reference. The parietal channels are relatively close to our main channels of interest (i.e. the central channels), and P4 is also relatively close to the original reference (right mastoid).

As can be seen in Supplemental Figures A1 to A12, with a parietal reference all event-related potentials (ERPs) are markedly reduced in amplitude as compared to the figures presented in our manuscript with data referenced to electrode A2. This is especially apparent at the parietal electrodes. These amplitude reductions are due to the effect of taking electrodes as a reference that show clear neural activity in response to the tone stimuli. Because the ERP signal present at a given reference electrode is subtracted from the signal present at all other electrodes, the result is reduced amplitudes at the electrodes close to the chosen reference electrode. This is why, ideally, one should 
choose a reference electrode that is far removed from the signals of interest and hence this is the main reason why we took A2 as our final reference (instead of, for instance, a single midline electrode on the head).

Furthermore, as can be observed in the standard (Std) and novel stimulus (NOV) conditions (in which between-group effects in the original A2 referenced data were observed), the ERPs from the data re-referenced to P3, re-referenced to P4, or re-referenced to the average of P3 and P4 look nearly identical across all groups (see Supplemental Figures A1, $\mathrm{A} 5, \mathrm{~A} 9$ and $\mathrm{A} 4, \mathrm{~A} 8, \mathrm{~A} 12$ ). There seem to be some very small left-right hemisphere reference effects visible in the ERP responses to the duration-deviant (DD) stimuli (see Supplemental Figures A2, A6, and A10) and the pitch-deviant (PD) stimuli (see Supplemental Figures A3, A7, and A11) in all study groups. However, because we did not observe group differences in these stimuli in our original A2 referenced data, we did not perform any follow-up analysis and refrained from making any further inferences regarding these stimuli. Therefore, the observed hemispheric reference effects (if any) in the re-referenced data have no impact on our original results and conclusions. Importantly, the results from the re-referenced data show that even if it would have been possible to re-reference our entire dataset to the average of the left and right mastoid electrodes, the results (at least in the case of the standard and novel stimuli and most likely also in the case of the pitch- and duration-deviant stimuli) would look almost identical to the results computed with a right mastoid reference electrode and therefore our current conclusions would not change.

Experimental procedure. In a typical passive auditory task paradigm, no behavioral responses to any of the occurring stimuli are generally required, the stimuli that are presented are auditory, and rarely occurring "oddball" stimuli are interspersed with often-occurring "standard" stimuli. However, in this experiment, we concurrently employed a video with low volume. Because children with autism spectrum disorders (ASD) often do not tolerate wearing anything inside the ear, we opted for presenting the sounds over external speakers and did not use in-ear headphones. We made sure that the standard and oddball stimuli occurring in the background ( $\sim 80 \mathrm{~dB}$ sound pressure level (SPL)) were louder than the sound stream coming from the video $(<60 \mathrm{~dB}$ SPL). A difference of $20 \mathrm{~dB}$ may seem small, but the decibel scale is logarithmic and a $20 \mathrm{~dB}$ increase in gain results in a four times increase in the perceived loudness (Warren, 1970, 1973).

Our data show that the children were capable of processing the background sounds while watching the video, as we observe clear-cut ERPs to all auditory stimulus conditions across all experimental groups. The validity of our procedure is also underscored by the fact that the ERPs resemble the classic P1/N1(N2) complex and P3a that typically occur in a passive auditory oddball paradigm.
The reason we opted to use a task paradigm in which a video with low sound was applied was because of the suitability for use in young children with cognitive impairments such as autism and developmental delay. Use of a video with low volume had two purposes: (a) it kept the participating children engaged and sitting still for acceptably long periods of time and hence facilitated the ability to obtain clean ERP data; and (b) it ensured that participants' attention was directed away from the tone stimuli occurring in the background. This procedure enabled us to assess neural markers of both conscious (P3a) and unconscious deviance detection processes ( $\mathrm{P} 1 /$ N1(N2)).

As we acknowledge in the Discussion section of our paper, we cannot completely rule out that children with ASD did in fact have more difficulties in processing competing auditory stimuli than typically developing children. However, even if we accept this possibility, the fact that under these conditions significant differences with developmentally delayed or typically developing children are observed is by itself an interesting finding and provides valuable information for researchers and clinicians working with these children, especially because distractors of various sorts are commonly present in real-life settings. Furthermore, if attentional orienting to novel stimuli is reduced in children with ASD when competing auditory stimuli are present, this constitutes an important avenue for further research into this topic.

Appendix 2. Means and standard deviations of the ERP components by electrode.

\begin{tabular}{|c|c|c|c|c|}
\hline \multirow{2}{*}{$\begin{array}{l}\text { ERP } \\
\text { components }\end{array}$} & \multirow[t]{2}{*}{ Electrode } & \multirow{2}{*}{$\frac{A S D}{\text { Mean }(S D)}$} & \multirow{2}{*}{$\frac{D D}{\text { Mean }(S D)}$} & \multirow{2}{*}{$\begin{array}{l}\text { TD } \\
\text { Mean } \\
(S D)\end{array}$} \\
\hline & & & & \\
\hline \multirow[t]{9}{*}{ Standard PI } & F3 & I. $.3(0.7)$ & $\mathrm{I} .4(0.9)$ & I.5 (0.8) \\
\hline & $\mathrm{Fz}$ & I.3 (0.7) & $\mathrm{I} .5(0.9)$ & I.5 (0.7) \\
\hline & $\mathrm{F} 4$ & I.2(0.6) & I.5 (0.8) & I.5 (0.7) \\
\hline & $\mathrm{C} 3$ & I. $3(0.7)$ & I.5 (0.8) & I.7 (0.7) \\
\hline & $\mathrm{Cz}$ & $\mathrm{I} .3(0.7)$ & $1.6(0.9)$ & $1.6(0.7)$ \\
\hline & $\mathrm{C} 4$ & I.3 (0.7) & I.5 (0.8) & $\mathrm{I} .7(0.8)$ \\
\hline & P3 & $0.9(0.6)$ & $0.8(0.6)$ & I.I (0.6) \\
\hline & $\mathrm{Pz}$ & $0.9(0.6)$ & $0.8(0.8)$ & I.I (0.6) \\
\hline & P4 & $0.8(0.5)$ & $0.8(0.7)$ & $1.0(0.6)$ \\
\hline \multirow[t]{9}{*}{ Standard N2 } & F3 & $-0.9(0.8)$ & $-0.8(I)$ & $-1.5(1.3)$ \\
\hline & $\mathrm{Fz}$ & $-0.9(0.7)$ & $-0.8(I)$ & $-1.5(1.3)$ \\
\hline & $\mathrm{F} 4$ & $-1.0(0.8)$ & $-0.7(1.1)$ & $-1.5(1.3)$ \\
\hline & $\mathrm{C} 3$ & $-1.2(0.9)$ & $-0.9(1.1)$ & $-1.6(1.3)$ \\
\hline & $\mathrm{Cz}$ & $-I . I(0.9)$ & $-0.8(1.1)$ & $-1.6(1.3)$ \\
\hline & $\mathrm{C} 4$ & $-I . I(0.9)$ & $-0.9(1.3)$ & $-1.7(1.3)$ \\
\hline & P3 & $-0.8(0.6)$ & $-0.5(0.8)$ & $-1.1(0.9)$ \\
\hline & $\mathrm{Pz}$ & $-0.7(0.6)$ & $-0.7(0.9)$ & $-1.1(I)$ \\
\hline & $\mathrm{P} 4$ & $-0.7(0.6)$ & $-0.6(0.8)$ & $-I(0.8)$ \\
\hline
\end{tabular}

(Continued) 
Appendix 2. (Continued)

\begin{tabular}{|c|c|c|c|c|}
\hline \multirow{2}{*}{$\begin{array}{l}\text { ERP } \\
\text { components }\end{array}$} & \multirow{2}{*}{ Electrode } & ASD & DD & TD \\
\hline & & Mean (SD) & Mean (SD) & Mear \\
\hline
\end{tabular}

$(S D)$

Pitch-deviant

PI

N2

Durationdeviant $\mathrm{PI}$

Durationdeviant N2

$\begin{array}{llll}\text { F3 } & 2.6(1.9) & 2.4(2.7) & 2.4(1.7) \\ \text { Fz } & 2.6(1.7) & 2.4(2.5) & 2.6(1.8) \\ \text { F4 } & 2.4(2.0) & 2.4(2.6) & 2.6(1.8) \\ \text { C3 } & 2.7(2.3) & 2.2(2.3) & 2.7(1.7) \\ \text { Cz } & 2.5(2.2) & 2.9(2.8) & 2.4(1.9) \\ \text { C4 } & 2.2(1.9) & 2.6(2.4) & 2.6(1.7) \\ \text { P3 } & 2.1(1.9) & 2.1(1.8) & 1.9(1.6) \\ \text { Pz } & 2.1(2.2) & 2.3(2.1) & 2.0(1.7) \\ \text { P4 } & 1.7(1.9) & 2.4(1.7) & 1.7(1.7)\end{array}$

(

F3 $\quad-0.4(1.8) \quad-0.2(1.6) \quad-0.7(2.0)$

$\mathrm{Fz} \quad-0.5(\mathrm{I} .6) \quad-0.6(\mathrm{I} .3) \quad-0.7(2.0)$

F4 $\quad-0.6(1.7) \quad-0.8(1.7) \quad-0.5(2.2)$

C3 $\quad-0.8(1.9) \quad-0.5(2.6) \quad-0.8(2.1)$

$\mathrm{Cz} \quad-0.7(\mathrm{I} .7) \quad-0.5(2.6) \quad-1.0(2.1)$

C4 $\quad-0.8(1.8) \quad-0.5(2.4) \quad-0.8(2.3)$

P3 $\quad-0.6(1.9) \quad-0.6(2.2) \quad-0.6(1.4)$

$\mathrm{Pz} \quad-0.4(1.6) \quad-1.0(2.4) \quad-0.8(1.4)$

P4 $\quad-0.5(1.5) \quad-0.9(2.2) \quad-0.7(1.5)$

\begin{tabular}{|c|c|c|c|c|}
\hline \multirow[t]{9}{*}{ deviant PI } & F3 & I.8 (I.7) & $2.0(2)$ & I.5 (I.5) \\
\hline & $\mathrm{Fz}$ & $1.9(1.6)$ & $2.0(2.2)$ & I.6 (I.5) \\
\hline & F4 & $1.9(1.5)$ & $2.3(1.8)$ & $1.8(1.5)$ \\
\hline & $\mathrm{C} 3$ & I.8 (I.3) & $2.0(1.8)$ & $1.9(1.4)$ \\
\hline & $\mathrm{Cz}$ & I.7 (I.4) & $2.0(2.2)$ & $2.1(1.6)$ \\
\hline & $\mathrm{C} 4$ & $1.9(1.5)$ & $2.0(1.8)$ & $2.2(1.6)$ \\
\hline & P3 & I.5 (I.3) & I.2 (I.5) & I.8 (I.5) \\
\hline & $\mathrm{Pz}$ & I.6 (I.2) & I.3 (1.8) & $1.9(1.6)$ \\
\hline & P4 & I.6 (I.5) & 0.9 (I.7) & $\mathrm{I} .7(\mathrm{I} .4)$ \\
\hline \multirow[t]{3}{*}{$\begin{array}{l}\text { Duration- } \\
\text { deviant N2 }\end{array}$} & F3 & $-1.6(2.2)$ & $-1.6(2.3)$ & $-1.9(1.7)$ \\
\hline & $\mathrm{Fz}$ & $-1.5(2.0)$ & $-1.2(2.6)$ & $-2.0(1.7)$ \\
\hline & $\mathrm{F} 4$ & $-1.4(2.0)$ & $-0.7(2.3)$ & $-1.9(2.0)$ \\
\hline
\end{tabular}

(Continued)
Appendix 2. (Continued)

\begin{tabular}{|c|c|c|c|c|}
\hline \multirow{2}{*}{$\begin{array}{l}\text { ERP } \\
\text { components }\end{array}$} & \multirow[t]{2}{*}{ Electrode } & \multirow{2}{*}{$\frac{\text { ASD }}{\text { Mean }(S D)}$} & \multirow{2}{*}{$\frac{\mathrm{DD}}{\text { Mean }(S D)}$} & \multirow{2}{*}{$\begin{array}{l}\text { TD } \\
\text { Mean } \\
(S D)\end{array}$} \\
\hline & & & & \\
\hline & $\mathrm{C} 3$ & $-1.6(1.8)$ & $-1.7(2.7)$ & $-2.1(1.7)$ \\
\hline & $\mathrm{Cz}$ & $-1.7(2.1)$ & $-1.7(3.4)$ & $-2.1(1.8)$ \\
\hline & $\mathrm{C} 4$ & $-1.5(1.8)$ & $-1.2(2.4)$ & $-2.0(1.7)$ \\
\hline & P3 & $-1.5(1.9)$ & $-1.9(2.2)$ & $-1.4(1.4)$ \\
\hline & $\mathrm{Pz}$ & $-1.3(1.8)$ & $-2.0(2.7)$ & $-1.6(1.6)$ \\
\hline \multirow[t]{9}{*}{ Novel P3a } & F3 & $3.2(2.0)$ & $5.4(2.4)$ & $4.3(2.2)$ \\
\hline & $\mathrm{Fz}$ & $3.4(2.1)$ & $5.3(2.5)$ & $4.6(2.0)$ \\
\hline & $\mathrm{F} 4$ & $3.4(2.0)$ & $4.8(2.2)$ & $4.4(2.0)$ \\
\hline & C3 & $3.8(2.1)$ & $5.2(3.2)$ & $4.5(1.9)$ \\
\hline & $\mathrm{Cz}$ & $3.8(2.1)$ & $5.2(3.4)$ & $5.1(2.1)$ \\
\hline & $\mathrm{C} 4$ & $3.5(2.0)$ & $4.8(3.0)$ & $4.4(2.0)$ \\
\hline & P3 & $1.9(2.0)$ & $3.2(2.5)$ & $2.9(1.8)$ \\
\hline & $\mathrm{Pz}$ & $2.5(1.6)$ & $3.7(2.7)$ & 3.5 (1.9) \\
\hline & P4 & $1.9(1.7)$ & $2.7(2.8)$ & $2.7(1.6)$ \\
\hline
\end{tabular}

ERP: event-related potentials; ASD: autism spectrum disorder; DD: developmental delay; TD: typical development.

Appendix 3. Mean $\pm S D$ latency of ERP components for each group by condition.

\begin{tabular}{llll}
\hline & ASD $(n=28)$ & DD $(n=17)$ & TD $(n=39)$ \\
\hline Standard & & & \\
PI & $0.11 \pm 0.02$ & $0.11 \pm 0.02$ & $0.11 \pm 0.02$ \\
N2 & $0.24 \pm 0.02$ & $0.24 \pm 0.02$ & $0.24 \pm 0.02$ \\
Pitch deviant & & & \\
PI & $0.14 \pm 0.03$ & $0.13 \pm 0.04$ & $0.13 \pm 0.03$ \\
N2 & $0.23 \pm 0.03$ & $0.23 \pm 0.04$ & $0.23 \pm 0.03$ \\
Duration deviant & & & \\
PI & $0.11 \pm 0.03$ & $0.11 \pm 0.03$ & $0.11 \pm 0.03$ \\
N2 & $0.22 \pm 0.04$ & $0.21 \pm 0.04$ & $0.23 \pm 0.03$ \\
Novel & & & \\
P3a & $0.26 \pm 0.05$ & $0.26 \pm 0.04$ & $0.25 \pm 0.04$ \\
\hline
\end{tabular}

ASD: autism spectrum disorder; DD: developmental delay; TD: typical development. 